Richard G. Anderson is an assistant vice president and economist at the Federal Reserve Bank of St. Louis. Robert H. Rasche is a professor of economics at Michigan State University and a visiting scholar at the Federal Reserve Bank of St. Louis. We thank Cindy Gleit and Daniel Steiner for excellent research assistance. We also thank the staff of the Division of Monetary Affairs, Board of Governors of the Federal Reserve System, for providing the data used in this article.

\section{Measuring the Adjusted Monetary Base in An Era of Financial Change}

\section{Richard G. Anderson and Robert H. Rasche}

$\mathrm{T}$ he adjusted monetary base is an index that measures the effects on a central bank's balance sheet of its open market operations, discount window lending, unsterilized foreign exchange market intervention, and changes in statutory reserve requirements. Such an index is important because the long-run path of a monetary economy's price level is primarily determined by the path of the central bank's balance sheet, adjusted for the effects of changes in statutory reserve requirements.

The St. Louis adjusted monetary base equals the sum of the monetary (or source) base and the reserve adjustment magnitude (RAM). This article presents a revised measure of the monetary base and a new RAM. The revised measure of the monetary base differs from previous measures by including all Federal Reserve Bank deposits held by domestic depository institutions; previous measures have excluded the aggregate amount of depository institutions' required clearing balance contracts with Federal Reserve Banks. The new RAM recognizes that, since the Monetary Control Act of 1980, an increasing proportion of depository institutions have not significantly changed their demand for base money (vault cash and deposits at
Federal Reserve Banks) relative to transactions deposits following changes in statutory reserve requirements. Previous RAM adjustments have assumed that depository institutions would match changes in their statutory required reserves about dollar-for-dollar with changes in their holdings of base money, following a change in reserve-requirement ratios. The new RAM, constructed from fifteen years of weekly data on more than 10,000 individual depository institutions, measures more precisely the change in the amount of base money demanded by depositories following changes in reserverequirement ratios than did previous RAM adjustments based on aggregate data.

\section{THE REVISED MONETARY BASE}

The measure of the monetary base that was published by the Federal Reserve Bank of St. Louis through September 1996 included most, but not all, deposits at Federal Reserve Banks held by domestic depository institutions. The new measure, presented in this article and published by the Bank since October 1996, includes all such deposits. The revision increases the level of the base by an amount that varies from zero in 1980 up to about $\$ 6$ billion in 1994 and 1996.

Sources and uses of high-powered money for the U.S. economy in December 1995 are shown in Table 1. ${ }^{1}$ M ost of the high-powered money supplied by the Federal Reserve and the Treasury is represented by currency in circulation and the deposits of domestic financial institutions at Federal Reserve Banks; together, these constitute the monetary base. ${ }^{2}$ The old measure of the St. Louis monetary base (line 6) equals the sum of currency in circulation outside the Treasury and Federal Reserve (line 6a) plus the "reserve balances" of depository institutions (line
1 The concept of high-powered money used in this section is slightly broader than the concept used by Friedman and Schwartz (1963).

2 This concept also is widely referred to as the source base; see for example Andersen and Jordan (1968). Our usage conforms to the earlier practice of labeling it "the monetary base." 


\section{Current and Revised Measures of the Monetary Base, December $1995 *$}

Factors Supplying
Base Money

(1) Reserve Bank credit (a)Securities held by the Federal Reserve

(b) Loans to depository institutions

387.132

(c) Federal Reserve float

(d) Other Federal Reserve assets

Total Reserve Bank credit

(2) Gold stock

11.050

(3) SDR certificates

10.168

(4) US Treasury currency and coin outstanding

$\underline{23.969}$

Total supply of base

money other than Reserve

Bank credit

0.209

1.223

$\underline{32.212}$

420.776

(5) Total supply of base money

465.963

* $\$$ billions, not seasonally adjusted.

Components may not add to totals due to rounding.

Source: Board of Governors of the Federal Reserve System.

Factors Using Base Money: Current Measure of the Monetary Base

(6) The Monetary Base:

Current Measure

(a) Currency and coin in circulation

419.615

(b) Reserve balances of depository institutions at Federal Reserve Banks

Total monetary base

(7) Uses of base money other than as the monetary base

(a) Treasury cash holdings

0.271

(b) Deposits of other than domestic financial institutions at Federal Reserve Banks

(c) Other Federal Reserve liabilities and capital

7.349

$\underline{45.187}$

(d) Deposits, other than reserve balances, of domestic financial institutions at Federal Reserve Banks, induding contractual amount of required dearing balances

Total other factors using base money
Factors Using Base Money: Revised Measure of the Monetary Base

(8) The Monetary Base:

Revised Measure

(a) Currency and coin in circulation

419.615

(b) Deposits of financial institutions at Federal Reserve Banks (revised measure)

Total monetary base

$\underline{25.888}$

440.016

(9) Uses other than as the monetary base

(a) Treasury cash

0.271

(b) Deposits of other than domestic financial institutions at Federal Reserve Banks

7.349

(c) Other Federal Reserve liabilities and capital

$\underline{12.841}$

Total other factors using base money (revised measure)

20.460 6b). Reserve balances, measured by subtracting the aggregate amount of depository institutions' required clearing balance contracts from their aggregate Federal Reserve deposits, is an accounting concept intended to measure the aggregate amount of high-powered money available to support deposit expansion. Uses of highpowered money other than as the monetary base, including their use to satisfy required clearing balance contracts, were about $\$ 25$ billion in December 1995 (line 7).

The new measure of the monetary base (line 8 ) equals the sum of currency in circulation (line 8a) plus all Federal Reserve deposits held by domestic depository institutions (line 8b). The new measure recognizes the similarity between the Federal Reserve deposits classified as reserves balances (line $6 \mathrm{~b}$ ) and those classified as held to satisfy required clearing balance contracts (line 7d). Both categories of deposits are used by depository institutions to settle interbank payments, and both are available to satisfy legal reserve requirements (al beit perhaps at the cost of failing to satisfy a required clearing balance contract). Including in the monetary base those Federal Reserve deposits putatively held to satisfy required clearing balance contracts increases the amount of Federal Reserve deposits in the base by about one-fourth.

Our new measure of the monetary base is suggested by the definition of Bal bach and Burger (1976):

... (the monetary base) can therefore be identified in any monetary system 
by ascertaining and summing the following:

1. those assets which the consolidated banking sector uses to settle interbank debt; and

2. those items, aside from bank liabili ties, which are used as money;

and by the definition of the Advisory Commission on M onetary Statistics (1976, p. 8):

$W$ ith respect to monetary aggregates, one basis for defining such a total is to regard money as corresponding to assets that are generally used to discharge obligations and that are not the explicit liability of nongovernmental entities in the society. Traditionally, such assets have corresponded to specie. In the United States today they correspond primarily to the non-interest-bearing fiat issues of the ultimate monetary authority. The terms "high-powered money" and "monetary base" have been used to refer to this total. We shall refer to it as "the base."

For the United States today the base includes all currency outside the Federal Reserve and the Treasury plus all bank deposits at Federal Reserve Banks.

Although broader than the old measure it replaces, the new measure of the monetary base excludes an important asset that these definitions suggest should be included: the amount of intraday credit, in the form of Federal Reserve deposits, used by banks for interbank payments. During 1994, such intraday deposits averaged approximately $\$ 50$ billion, or nearly twice the close-of-business-day amount of Federal Reserve deposits included in the monetary base (see Richards, 1995, p. 1066). The major barrier to inclusion of intraday deposits is the lack of timely published data: close-of-business deposit levels are published weekly on the Board of Governors' H.4.1 statistical release, while intraday credit is not published in any release. ${ }^{3}$

The need to revise the measure of the monetary base arises from changes in U.S. financial markets since the M onetary Control Act of 1980. The Act significantly changed the demand for Federal Reserve deposits. Prior to the Act, almost all deposits at Federal Reserve Banks were held by member banks of the Federal Reserve System. ${ }^{4}$ Banks used these balances both to satisfy reserve requirements and to make payments on behalf of customers. For most member banks, the latter came "free": the amount of reserves that they were required to hold against deposits was more than sufficient to satisfy any demands arising from interbank payments (perhaps with some intraday Federal Reserve overdraft credit). Nonmember banks and thrifts, lacking access to the Federal Reserve's books for final settlement of payments, made interbank payments and settled checks through correspondent accounts at member banks.

The Monetary Control Act made nonmember institutions subject to Federal Reserve System reserve requirements and, at the same time, gave them direct access to the payments system through deposits at the Federal Reserve Banks (see Gilbert and Summers, 1996). Because the new reserve requirements were phased in for these institutions over an eight-year period, many initially found their vault cash more than sufficient to satisfy the requirements. Holding only small amounts of Federal Reserve deposits, some institutions found that overdrafts on Federal Reserve accounts became a problem (see Federal Reserve Bulletin, March 1981, pp. 247-49 and December 1982, p. 756). As a result, during the early 1980 s the Federal Reserve required some depository institutions that used Federal Reserve payments services to maintain so-called required clearing balances, or levels of Federal Reserve deposits above and beyond the amounts necessary to satisfy the institutions' statutory reserve requirements. To offset the cost of holding these balances and make the requirement more palatable, the Federal Reserve paid the institutions, at (approximately) the federal funds rate, "earnings credits" that could be used only
3 The revised measure of the base, like previous measures, excludes Federal Reserve deposits held by the U.S. Treasury and by foreign central banks, included in lines $7 \mathrm{~b}$ and gb of Table 1. These deposits are not used to make interbank payments nor to discharge debts of nongovernmental units', see Advisory Committee on Monetary Statistics (1976).

${ }^{4}$ Nonmember banks held small amounts of Federal Reserve deposits before 1980, apparently used for clearing house payments. The measure of the monetary base proposed by Brunner (1961) excluded these deposits. The measures constructed by Cagan (1965) and Friedman and Schwartz (1963, appendix A) include (estimates of) these deposits. 
to defray charges for Federal Reserve priced services such as check clearing and wire transfers.

A clear statement of the rationale for the exclusion of required clearing balances from the current measure of the monetary base is provided by Gilbert (1983), p. 23n:

Depository institutions maintain clearing balances at Federal Reserve Banks as a means of payment for the fees Federal Reserve Banks now charge for services. Depository institutions receive implicit interest on their clearing balances at the federal funds rate, which may be used to pay the fees on services. Required clearing balances are subtracted in computing the [ monetary] source base because clearing balances are part of total reserve balances held by depository institutions at Federal Reserve Banks, but are not related to the levels of deposit liabilities. ${ }^{5}$

Perhaps reasonable at the time, the required clearing balance contract has evolved into a flexible, voluntary tool of depository institution cash management. Although the contract obliges a depository institution to maintain a larger Federal Reserve deposit than is necessary to satisfy its required reserves, the deposit is neither a distinct type nor separate category of deposit: all of the funds are available to settle interbank payments and may be converted to vault cash if necessary. ${ }^{6}$

During the mid-1980s, and especially the quotation, required clearing balances are not (and never have been) included in published Federal Reserve data on reserve balances.

6 There is one exception to this statement. A nonmember depository institution may have a separate clearing balance deposit account at a Federal Reserve Bank if it satisfies its required reserves via a passthrough contract with another eligible depository institution.

7 See Feinman (1993) and Hilton, Cohen and Koonmen (1993). ting it to use all its Federal Reserve deposits to satisfy its statutory requirements. At the same time, the Federal Reserve deposits used to satisfy the clearing balance contract accumulate earnings credits at about the federal funds rate.

The Federal Reserve deposits held to satisfy a required clearing balance contract act as a buffer stock relative to the deposits needed to satisfy statutory reserve requirements because, under Federal Reserve accounting rules, balances in a depository's Federal Reserve account are applied first to satisfy its statutory required reserves and only thereafter to satisfy the clearing balance requirement. Hence, when an institution's Federal Reserve deposit balance falls below its expectation, the shortage is recorded in the Federal Reserve's accounting system as a deficiency on a clearing balance requirement rather than as a deficiency on a statutory reserve requirement (provided the sum of vault cash and Federal Reserve deposits exceeds the institution's required reserves).

No penalties are imposed for small deficiencies on voluntary clearing balance contracts, and larger shortfalls are penalized at only a 2 or 4 percent annual interest rate (see Stevens, 1993). Deficiencies relative to required reserves are subject to significant penalties and "administrative counseling," while comparable deficiencies relative to a clearing requirement are subject to minimal penalties. An institution that sometimes has been forced to borrow at either the discount window or a penal ty federal funds rate to cover reserve deficiencies may find the required clearing balance account comforting.

By 1985, about 4500 institutions had clearing balance contracts, totaling approximately $\$ 1.2$ billion (Figure 1 ). These numbers were about the same in the third quarter of 1990, before the December 1990 reduction in reserve requirements on nonpersonal time deposits and certain other liabilities. Two years later, during the third quarter of 1992, the amount of contracted required clearing balances had 
nearly tripled to approximately $\$ 4.5$ billion while the number of institutions had increased to about $4700 .^{8}$

In summary, proper measures of the monetary base should include deposits held at Federal Reserve Banks to satisfy required clearing balance contracts, for several reasons:

- First, the size of a contract, and hence the amount of additional Federal Reserve deposits that must be held to satisfy the contract, is determined by a depository institution's asset and liability management strategy, not by any regulation. An institution may change the size of its clearing balance commitment when it desires, appropriate to its business needs. ${ }^{9}$ "Required" clearing balance contracts are voluntary commitments.

- Second, the Federal Reserve deposits held to satisfy a clearing balance contract are available to settle interbank payments in the same way as other Federal Reserve deposits. These deposits are maintained in the same Federal Reserve account that contains deposits used to satisfy statutory reserve requirements.

- Finally, the Federal Reserve deposits used to satisfy required clearing balance contracts are supplied by the Federal Reserve, through actions such as open market operations, in the same way as other high-powered money. They are not a distinct type of funds.

Including the amount of required clearing balance contracts in the monetary base is not without objection. Some depository institutions seem to adjust the size of their contract inversely to changes in the federal funds rate, seeking perhaps to generate only enough earnings credits to pay for their use of the Federal Reserve's priced services. For these institutions, the demand for Federal Reserve deposits may be highly interest-elastic and largely unrelated to either liquidity management or lending decisions. If so, argue some analysts, required clearing balances should be excluded from the monetary base.

\section{Figure 1}

\section{Required Clearing Balance Contract Amounts}

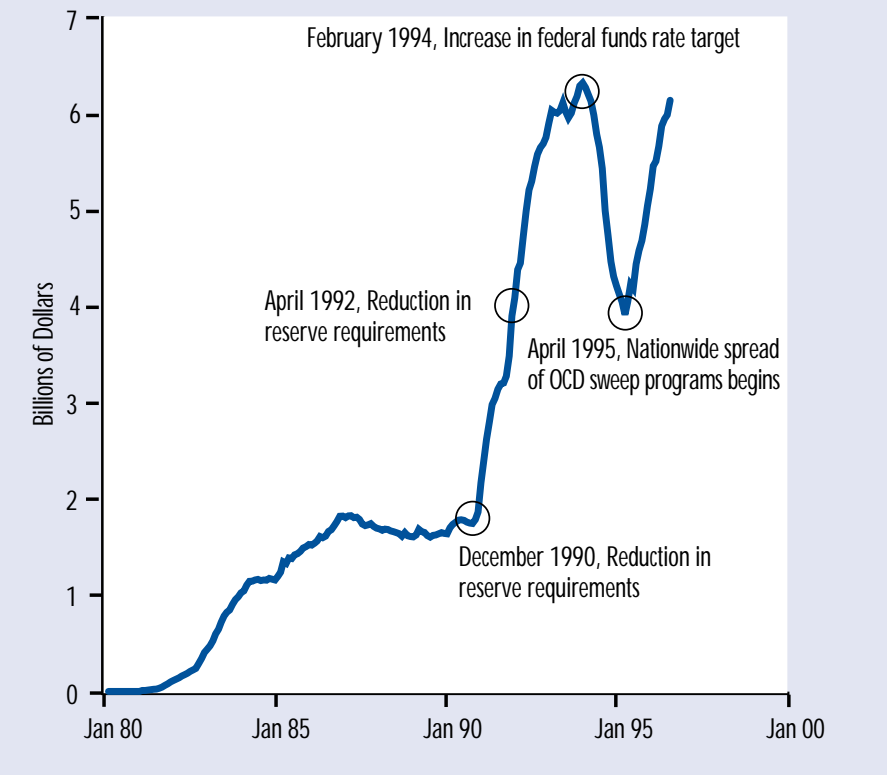

Relatively simple macroeconomic analysis shows that this argument has no implications for definition or measurement of the adjusted monetary base. In previous articles, we have explored the dependence of most money multiplier components, such as $k$ and e, on economic variables such as interest rates and income (Anderson and Rasche, 1982; Anderson, Johannes and Rasche, 1983). Although it seems likely that including required clearing balances in the monetary base will increase the interest el asticity of the excess reserve ratio, e, this increase has no implications for the importance of the adjusted base as a policy indicator in models where changes in the adjusted monetary base are transmitted to the economy solely through changes in a monetary aggregate, $M$. In these models, the role of the adjusted monetary base as an indicator of the stance of monetary policy is independent of the size of the elasticity of multiplier components such as $k$ (the nonbank public's desired ratio of currency to checkable deposits) and e (depository institutions' desired ratio of excess reserves to checkable deposits) with respect to
${ }^{8}$ The actual amount of Federal Reserve deposits used to satisfy depositories' clearing balance contracts is not available. These data are the nominal contracted amounts.

${ }^{9}$ However, Federal Reserve operating rules generally discourage changes more frequently than once a month, or approximately every third or fourth maintenance period. 
variables such income and interest rates. For further discussion, see Anderson and Rasche (1996b).

Comparison of U.S. and foreign payments systems reinforces our decision to include the aggregate amount of required clearing balance contracts in the monetary base. In some countries, depository institutions' need to settle interbank payments in central bank deposits has been cited as a justification for effective, binding statutory reserve requirements (Deutsche Bundesbank, 1994, pp. 70-80). In countries without statutory reserve requirements, all central bank deposits held by depository institutions are clearing balances; yet, such deposits play an important role in the central bank's monetary policy (see Bank of Canada, 1987, 1989, 1991; Bank for International Settlements, 1993).

\section{ADJ USTING THE MONETARY BASE FOR CHANGES IN RESERVE REQUIREM ENTS}

The adjusted monetary base combines in a single index three Federal Reserve actions that affect the supply of the monetary base- open market operations, discount window lending, and unsterilized foreign exchange market interventionwith changes in statutory reserve requirements that affect depository institutions' demand for the monetary base. Hence, measuring the adjusted monetary base requires a mechanism that can translate changes in the demand for base money due to changes in statutory reserve requirements into equival ent changes in the supply of base money due to open market operations or similar actions. The reserve adjustment magnitude, or RAM, provides such a mechanism by measuring the amount by which the aggregate quantity of base money demanded by depository institutions during any given period has been affected by changes in reserve requirements, relative to a selected base period.

Combining the effects of changes in statutory reserve requirements with those from open market operations and similar instruments depends, implicitly or explicitly, on a model of depository institutions' demand for base money. Absent a fully worked out model of bank liquidity management and reserve demand, we use statistical tests to identify the characteristics of depositories that likely have, and have not, responded to changes in reserve requirements since 1980. Only the former set of institutions is included in our new RAM adjustment.

The original St. Louis adjusted monetary base published by Andersen and Jordan (1968) included an adjustment for "reserves released by changes in reserve requirements." The adjustment, constructed as suggested by Brunner (1961), added to the monetary base at each date the cumulative dollar amount by which past changes in reserve requirements had changed the level of required reserves. Although each change in reserve requirements was viewed as absorbing or liberating a certain dollar amount of required reserves, these amounts depended only on the amount of reservable deposits on the date of the reduction: They did not vary in later periods with changes in the levels of reservable deposits.

In 1977, Burger and Rasche (1977) showed that Brunner's adjustment for the effects of reserve-requirement ratio changes was inadequate because it did not consider the amount by which past changes in reserve-requirement ratios affected banks' current required reserves. They showed that a suitable adjustment must vary with current deposit levels if it is to remove the total effect of the change in reserve-requirement ratios from the monetary base multiplier (and no more). They proposed that the adjusted monetary base be measured as the sum of the monetary (source) base and a time-varying reserve adjustment magnitude (RAM) , a methodology that has generally been maintained in subsequent revisions of the St. Louis adjusted monetary base. ${ }^{10}$

Substantial changes in the structure of reserve requirements since 1980 suggest a reexamination of the Burger and Rasche 
methodology. We formalize their analysis by considering a model with two classes of institutions. Those in the first class resemble the member commercial banks considered by Burger and Rasche: Their required reserves exceed their vault cash, and they must hold deposits at Federal Reserve Banks to satisfy the balance of their statutory requirements. As a result, statutory reserve requirements play an important role in determining their demand for base money. Institutions in the second class find legal reserve requirements much less influential in their portfolio allocation decisions: Their level of required reserves is less than their vault cash, and they need not hold any deposits at Federal Reserve Banks to satisfy statutory requirements. The demand by these institutions for deposits at Federal Reserve Banks depends largely on their need to make interbank payments in immediately available funds on the books of the Federal Reserve Banks, and perhaps on Federal Reserve restrictions regarding daylight overdrafts. ${ }^{11}$

\section{Monetary Base Multipliers before 1980}

We begin with a model that reflects the institutional environment before the M onetary Control Act of 1980. Since our purpose is to illustrate the dependence of the RAM adjustment on the distribution of deposits among different classes of depository institutions, we separate member and nonmember banks more explicitly than have previous authors. ${ }^{12}$ We assume (1) a central bank that issues two liabilities, currency, $\mathrm{Cu}$, and reserve balances (that is, deposits at the central bank), RB, and (2) two types of depository institutions, indexed by superscripts $M$ and $\mathrm{N}$ (corresponding to member banks, and to non-member banks and thrifts, respectively), that issue demand $D=$ $D_{M}+D_{N}$ and time $T=T_{M}+T_{N}$ deposits. The two types of depositories are dissimilar in four characteristics:

- Type M institutions are subject to central bank reserve requirements against deposits that may be satisfied by holding either vault cash or deposits at the central bank.

- Government deposits are only at type $M$ institutions.

- Type $\mathrm{N}$ institutions hold deposits at type $M$ institutions but not vice versa.

- Type $\mathrm{N}$ institutions are not permitted to hold deposits at the central bank.

They are similar in two other ways:

- Both types of institutions hold vault cash to satisfy reserve requirements and/or to convert deposits into currency on demand.

- Both types of institutions issue deposits that the nonbank public regards as perfect substitutes.

We assume that transactions among banks, the government, and the nonbank public are settled in terms of currency, $\mathrm{Cu}$, demand deposits held by the government at type $M$ depositories, $D_{M}^{G}$, demand deposits held by the nonbank public at type $M$ and $N$ depositories, $D_{M}^{P}$ and $D_{N}^{P}$, respectively, and demand deposits held by type $\mathrm{N}$ at type $\mathrm{M}$ depositories, $\mathrm{D}_{\mathrm{M}}^{\mathrm{N}}$. (Throughout, superscripts refer to the owner of the deposit and subscripts to the issuer of the deposit.) Define

$$
D^{P}=D_{M}^{P}+D_{N}^{P} \text { and } D_{M}=D_{M}^{P}+D_{M}^{G}+D_{M}^{N} \text {, }
$$

and note that

$$
D^{P}=D_{M}+D_{N}^{P}-D_{M}^{G}-D_{M}^{N} \text {. }
$$

The Federal Reserve imposes reserve requirements against demand $D_{M}$ and time $T_{M}$ deposits at rates $r^{D}$ and $r^{T}$, respectively, such that the required reserves of a type $M$ institution are $R R=r^{D} D_{M}+r^{\top} T_{M}{ }^{13}$

The monetary base multiplier in this model is easily derived. Suppressing time subscripts, the monetary base is by definition

where

$$
\begin{aligned}
M B= & R B+C u \\
= & r^{D} D_{M}+r^{\top} T_{M}+k D^{P}+V C_{N}+ \\
& \left(V C_{M}+R B-r^{D} D_{M}-r^{\top} T_{M}\right) \\
= & \left(r^{D} d_{M}+r^{\top} t_{M}+k+v_{N}+e_{M}\right) D^{P},
\end{aligned}
$$

$\left(r^{D} D_{M}+r^{T} T_{M}\right)$ are the required reserves of type $M$ institutions,
${ }^{11}$ See for example Hancock and Wilcox (1996).

${ }^{12}$ Burger (1971) provides a similar analysis without as explicit a separation of different classes of institutions.

${ }^{13}$ Historically, some nonmember banks and thrifts faced stateimposed reserve requirements that had to be satisfied with holdings of vault cash, deposits in other banks, U.S Treasury bills or certain other liquid securities. See Gilbert (1978), Gambs and Rasche (1978), and Gilbert and Lovati (1978). 
$k D^{P}$ is currency held by the nonbank public,

$V C_{M}$ and $V C_{N}$ are vault cash held by type $\mathrm{M}$ and $\mathrm{N}$ institutions, respectively, RB are the deposits held by type $M$ institutions at the central bank,

$$
d_{M}=\frac{D_{M}}{D^{P}}, \quad t_{M}=\frac{T_{M}}{D^{P}}, \quad v_{N}=\frac{V C_{N}}{D^{P}},
$$

and $e_{M}=\frac{V C_{M}+R B-r^{D} D_{M}-r^{\top} T_{M}}{D^{P}}$.

The term $\left(V C_{M}+R B-r^{D} D_{M}-r^{\top} T_{M}\right)$ equals the amount of high-powered money, vault cash plus reserve balances, held by type $M$ institutions above and beyond their required reserves.

For clarity, it may be useful to relate these reserve constructs in our model to those currently published. The Federal Reserve Board's reserve measures differ from those of the Federal Reserve Bank of St. Louis by excluding surplus vault cash from the definition of excess reserves. For an individual depository institution i,

- if $V C_{i, M}>\left(r^{D} D_{i, M}+r^{\top} T_{i, M}\right)$, then the difference $\left(V C_{i, M}-r^{D} D_{i, M}+r^{\top} T_{i, M}\right)$ is referred to as surplus vault cash. If $V C_{i, M} \leq\left(r^{D} D_{i, M}+r^{\top} T_{i, M}\right)$, then surplus vault cash is zero.

- If $V C_{i, M}>\left(r^{D} D_{i, M}+r^{T} T_{i, M}\right)$ and $R B_{i, M}>0$, then $R B_{i, M}-R C B_{i, M}$ is referred to as excess reserves, where $R_{i, M}$ represents the total reserve balances held by depository institution $i$ at the Federal Reserve and $R C B_{i, M}$ is the amount of its required clearing bal ance contract (if any). Note that $R C B_{i, M}$ may be zero, and $R B_{i, M}-R C B_{i, M}$ may be negative. If $R B_{i, M}-R C B_{i, M}=0$, then excess reserves equal zero even though surplus vault cash is greater than zero.

- If $V C_{i, M}<\left(r^{D} D_{i, M}+r^{\top} T_{i, M}\right)$, then $R B_{i, M}-$ $R C B_{i, M}-\left(r^{D} D_{i, M}+r^{T} T_{i, M}-V C_{i, M}\right)$ is excess reserves.

${ }^{14}$ See Table 1.20 in the Federal Reserve Bulletin or the Board's weekly statistical release Aggregate Reserves of Depository Institutions and the Monetary Base. (H.3)
Measures of aggregate total and excess reserves published by the Board of Governors of the Federal Reserve System omit surplus vault cash and an amount of Federal Reserve deposits equal to depository institutions' required clearing balance con- tracts. ${ }^{14}$ The old reserve measures published by the Federal Reserve Bank of St. Louis through September 1996 (discussed in the previous section of this paper) included surplus vault cash but omitted required clearing balance contracts.

The monetary base multiplier for $\mathrm{M} 1$ is straightforward:

$$
\begin{aligned}
M 1 & =C u+D^{P}=(1+k) D^{P} \\
& =\left\{\frac{(1+k)}{r^{D} d_{M}+r^{\top} t_{M}+k+v_{N}+e_{M}}\right\} M B \\
& =m_{1}\left(r^{D}, r^{\top}, k, e_{M}, t, t_{M}, d_{M}, v_{N}\right) M B,
\end{aligned}
$$

and for $\mathrm{M} 2$,

$$
\begin{aligned}
M 2 & =C u+D^{P}+T=(1+k+t) D^{P} \\
& =\left\{\frac{(1+k+t)}{r^{D} d_{M}+r^{\top} t_{M}+k+v_{N}+e_{M}}\right\} M B \\
& =m_{2}\left(r^{D}, r^{\top}, k, e_{M}, t, t_{M}, d_{M}, v_{N}\right) M B, \\
\text { where } t & =\frac{(M 2-M 1)}{D^{P}}=\frac{\left(T_{M}+T_{N}\right)}{D^{P}} .
\end{aligned}
$$

The reserve adjustment to the monetary base, RAM, maps the effects of changes in reserve-requirement ratios into equivalent changes in the monetary base. The effect of this mapping is to define new adjustedmonetary-base multipliers for the monetary aggregates $\mathrm{M} 1$ and $\mathrm{M} 2$ that are invariant to changes in the reserve-requirement ratios $r^{D}$ and $r^{\top}$, denoted as $m_{1 b}\left(r^{D}, r^{\top}, k, e_{M}, t, t_{M}, d_{M}, v_{N}\right)$ and $m_{2 b}\left(r^{D}, r^{\top}, k, e_{M}, t, t_{M}, d_{M}, v_{N}\right)$, respectively. At the same time, the adjustment should not change the response of these multipliers to arguments other than the reserverequirement ratios $r^{D}$ and $r^{\top}$, when compared to the responses of $m_{1 b}\left(r^{D}, r^{\top}, k, e_{M}, t, t_{M}, d_{M}, v_{N}\right)$ and $m_{2 b}\left(r^{D}, r^{\top}, k, e_{M}, t, t_{M}, d_{M}, v_{N}\right)$.

Letting the adjusted monetary base be defined as $A M B=M B+R A M$, we have:

$$
M 1=m_{1 b}(M B+R A M)=m_{1 b} A M B
$$

where

$$
m_{1 b}=\frac{(1+k)}{r_{0}^{D} d_{M}+r_{0}^{\top} t_{M}+k+v_{N}+e_{M}} \text {, and }
$$


$r_{0}^{D}$ and $r_{0}^{\top}$ are the reserve requirement ratios on transaction and time deposits in a chosen base period, respectively. The reserve adjustment magnitude,

$$
R A M=\left[\left(r_{0}^{D}-r_{t}^{D}\right) d_{M}+\left(r_{0}^{\top}-r_{t}^{T}\right) t_{M}\right] D^{P},
$$

maps the change in required reserves due to any change in reserve requirement ratios since the specified base period into an equivalent change in the monetary base.

Similarly, for $M 2$ we have

$$
M 2=m_{2 b} A M B=m_{2 b}(M B+R A M) \text {. }
$$

Noting that

$$
\begin{aligned}
& {[1+k+t] D^{P}=} \\
& m_{2 b}\left[r_{t}^{D} d_{m}+r_{t}^{\top} t_{m}+k+v_{N}+e_{m}\right] D^{P}+ \\
& m_{2 b}\left[\left(r_{0}^{D}-r_{t}^{\top}\right) d_{m}+\left(r_{0}^{\top}-r_{t}^{\top}\right) t_{m}\right] D^{P},
\end{aligned}
$$

then

$$
m_{2 b}=\frac{(1+k+t)}{r_{0}^{D} d_{m}+r_{0}^{\top} t_{m}+k+v_{N}+e_{m}},
$$

which is invariant to changes in the legal required reserve ratios $r^{D}$ and $r^{\top}$.

The above analysis may be extended to the case where type $M$ institutions (those subject to central bank reserve requirements) issue $\mathrm{i}=(1, \ldots, \mathrm{l})$ classes of transaction deposits and $\mathrm{j}=(1, \ldots$,$) ) classes of$ time deposits, each with possibly different reserve requirement ratios.

At type $M$ institutions, let

$$
\delta_{M i}=\frac{D_{M i}}{D^{P}} \text { and } \tau_{M j}=\frac{T_{M j}}{D^{P}}
$$

denote the ratios of the nonbank public's holdings of demand and time deposits in the $i^{\text {th }}$ and $j^{\text {th }}$ reserve classifications, respectively, to their total holdings of demand deposits, $D^{P}$. Then aggregate required reserves are ${ }^{15}$

$$
\left(\sum_{i=1}^{1} r_{M i}^{D} \delta_{M i}+\sum_{j=1}^{J} r_{M j}^{\top} \tau_{M j}\right) D^{P},
$$

and the monetary base multiplier is

$$
m_{1 b}=\frac{1+k}{\left(\sum_{i=1}^{1} r_{M i 0}^{D} \delta_{M i}+\sum_{j=1}^{J} r_{M j 0}^{\top} \tau_{M j}+k+v_{N}+e_{M}\right)} .
$$

N ote the presence of base-period reserve-requirement ratios for each class of deposit, $r_{M i 0}^{D}$ and $r_{M j 0}^{\top}$, in the denominator. The corresponding reserve adjustment magnitude is

$$
\begin{gathered}
\text { RAM }=\left(\sum_{i=1}^{1}\left(r_{M i 0}^{D}-r_{M i}^{D}\right) \delta_{M i}+\right. \\
\left.\sum_{j=1}^{j}\left(r_{M j 0}^{\top}-r_{M j}^{\top}\right) \tau_{M j}\right) D^{P} .
\end{gathered}
$$

Finally, as a caveat and extension to earlier remarks, note that the RAM adjustment does not make all money and credit multipliers invariant to changes in statutory reserve-requirement ratios. Consider the monetary-base multiplier for bank credit $(B C)$, or $m_{B C}$, defined by Brunner and Meltzer (1968) as BC = $\mathrm{m}_{\mathrm{BC}} \mathrm{MB}$ B. In our notation,

$$
m_{B C}=\frac{(1+t)-\left(r_{t}^{D} d_{m}+r_{t}^{\top} t_{m}+e_{m}+v_{N}\right)}{r_{t}^{D} d_{m}+r_{t}^{\top} t_{m}+k+e_{m}+v_{N}}
$$

[see Brunner and Meltzer (1968), equation A.8, p. 32]. Let the adjusted-monetary-base multiplier for bank credit be defined as

$$
B C=m_{B C b} A M B=m_{B C b}[M B+R A M] .
$$

Then:

$$
\begin{gathered}
{\left[(1+t)-\left(r_{t}^{D} d_{m}+r_{t}^{\top} t_{m}+e_{m}+v_{N}\right)\right] D^{p}=} \\
m_{B C b}\left[r_{t}^{D} d_{m}+r_{t}^{\top} t_{m}+e_{m}+v_{N}\right] D^{P}+ \\
m_{B C b}\left[\left(r_{0}^{D}-r_{t}^{D}\right) d_{m}+\left(r_{0}^{\top}-r_{t}^{\top}\right) t_{m}\right] D^{P},
\end{gathered}
$$

So

$$
m_{B C b}=\frac{(1+t)-\left(r_{t}^{D} d_{m}+r_{t}^{\top} t_{m}+e_{m}+v_{N}\right)}{r_{0}^{D} d_{m}+r_{0}^{\top} t_{m}+k+e_{m}+v_{N}},
$$

which is not invariant to change in legal required reserve ratios $r^{D}$ and $r^{\top}$. Thus, in models in which intermediated (bank) credit provides a channel of monetary policy independent of that provided by monetary aggregates, the adjusted monetary base defined above is not an ade-

\footnotetext{
${ }^{15}$ Recall that only type M institutions are subject to statutory reserve requirements in this model.
} 
quate indicator variable for the stance of monetary policy.

\section{Adjusting for Reserve Requirement Changes with "Economically Nonbound" Institutions}

For periods prior to late 1980 , depository institutions are easily separated into two groups based on their holdings of base money: M ember banks held vault cash, were subject to Federal Reserve System reserve requirements, and generally held deposits at Federal Reserve Banks; nonmember banks and thrifts held vault cash and were not eligible to hold deposits at Federal Reserve Banks.

Studies of the adjusted monetary base prior to 1980 generally assumed that member banks changed their holdings of base money about dollar-for-dollar following changes in their required reserves due to changes in reserve-requirement ratios. During that period, member banks held few excess reserves, and most banks likely faced reserve-requirement ratios sufficiently high to constrain their portfolio allocation decisions. ${ }^{16}$ The use of Federal Reserve deposits to settle interbank payments was little discussed. The general assumption among economists and banking analysts seemed to be that either banks' deposits at Federal Reserve Banks were more than adequate to absorb debits and originate payments, or that the Federal Reserve would supply adequate intraday credit. Banks also had very limited ability to alter their demand for base money by inducing customers to shift funds from transaction to nontransaction deposits. Time deposits, with the exception of large negotiable certificates of deposit, were subject to effective Regulation Q interest rate ceilings. Overall, both banks and their customers likely were sufficiently constrained that other multiplier components (such as the ratio of time and savings deposits to transaction deposits, or $\mathrm{t}$ ) were unaffected by changes in legal reserverequirement ratios on deposits.

Under this regime, the total amount of base money demanded by depositories equaled the sum of member banks' required and excess reserves, plus the vault cash held by other depositories. Because member banks applied essentially all their vault cash to satisfy reserve requirements, and because required clearing balances were approximately zero, excess reserves at member banks equaled the difference between their deposits at Federal Reserve Banks (denoted as RB) and the portion of their required reserves not satisfied by vault cash:

$$
E R_{M}=R B_{M}-\left(r^{D} D_{M}+r^{T} T_{M}-V C_{M}\right) \text {. }
$$

(Note that RB denotes both the reserve balances and total Federal Reserve Bank deposits held by member banks; without required clearing balance contracts, these are exactly the same.) Excess reserves for the banking system as a whole equaled the sum of excess reserves at member banks plus vault cash at nonmember banks, $V C_{N}$. The average aggregate excess reserve ratio was

$$
\mathrm{e}=\mathrm{e}_{\mathrm{M}}+\mathrm{v}_{\mathrm{N}}=\frac{E \mathrm{R}_{\mathrm{M}}+V C_{N}}{D^{P}} .
$$

Today's environment is considerably different. The M onetary Control Act extended reserve requirements to all depository institutions, reduced to zero required reserves on savings and personal time deposits, and significantly reduced other reserve requirements on member banks. During December 1990 and January 1991, reserve-requirement ratios on nonpersonal time deposits and Eurodollar liabilities were reduced to zero for all depository institutions. In A pril 1992, reserve-requirement ratios on transaction deposits were reduced to 10 percent from 12 percent. ${ }^{17}$ Depository institutions also gained greater freedom to adjust their mix of reservable and nonreservable deposits during the 1980s, following the end of Regulation Q ceilings on deposit offering rates.

Following implementation of the Monetary Control Act, many depository institutions found that their vault cash, al though largely held for retail business reasons, also satisfied their reserve requirements. ${ }^{18}$ In the Federal Reserve System, depository institutions that fully satisfy 
their required reserves with vault cash are known as "nonbound" institutions; other institutions are known as "bound" institutions. In this article, we refer to these institutions as L-N onbound and L-Bound, respectively. Table 2 shows the percentage distribution of L-Bound and L-N onbound depository institutions among depositories reporting data to the Federal Reserve for selected years from 1981-95. (The rows labeled E-Bound and E-N onbound are explained later.) Part A of the table includes only institutions that reported data weekly, while Part B includes institutions that reported quarterly and annually. ${ }^{19}$ In mid-1983, after the initial phase-in of the Monetary Control Act, about 40 percent of the total deposits reported by weekly-reporting institutions was at L-N onbound institutions; for all reporting institutions, shown in Part $B$, about 43 percent of deposits was at L-N onbound institutions. By mid-1989, these proportions had fallen to approximately 18 percent (in Part A) and 25 percent (in Part B). The 1990-91 reduction in reserverequirement ratios increased the proportion of total deposits at L-N onbound weekly reporting institutions to about 27 percent in 1991.

We regard L-N onbound institutions as facing no effective reserve requirementrelated constraint because they seem unlikely to change the asset mix of their portfolios following a change in statutory reserve requirements. L-N onbound institutions satisfy their required reserves with vault cash, and we assume that their holdings of vault cash are determined almost entirely by business needs, rather than by statutory reserve requirements. As a result, these institutions seem unlikely to change their portfolio mix of assets in response to a change in reserve-requirement ratios.

Vault cash held by L-N onbound depository institutions in excess of their required reserves is known as "surplus vault cash." Surplus vault cash is "surplus" only in the sense that some part of the bank's vault cash is not used to satisfy statutory reserve requirements. No statutory requirement determines a deposi- tory's vault cash; these amounts are voluntarily chosen by the institutions' managers. As such, they presumably reflect anticipated business of the institution, and hence are not surplus in the economic sense of indicating a portfolio disequilibrium. Surplus vault cash is included in both the old and new St. Louis' measures of the adjusted monetary base, and in the Board of Governors' measure of the monetary base, not adjusted for reserve requirement changes and not seasonally adjusted. It is excluded, however, from the Board of Governors' measure of the monetary base, adjusted for changes in reserve requirements.

Historical data on surplus vault cash are shown in Figure 2 (see page $\cdot \bullet$ ). Before 1959, vault cash could not be used to satisfy reserve requirements, so all vault cash was surplus. Surplus vault cash decreased sharply during 1959-60 when Federal Reserve member banks were gradually allowed to apply vault cash toward satisfying required reserves. (The fraction of vault cash eligible to satisfy required reserves increased linearly at the rate of one-twelfth per month, reaching 100 percent of vault cash in December 1960.) From 1961 to 1981, surplus vault cash equaled the vault cash held by nonmember banks and thrift institutions, since member banks applied virtually all their vault cash to satisfy reserve requirements. Surplus vault cash grew rapidly during the 1970 s as the fraction of banks that were members of the Federal Reserve System declined. Although the Monetary Control Act extended reserve requirements to all depository institutions, the requirements were phased in during 1980-1987. During these years, surplus vault cash generally decreased. During the later 1980s, surplus vault cash remained relatively constant but exhibited substantial seasonal variation.

Although the vault cash holdings of L-Bound institutions are less than their required reserves, some of these institutions also might not be constrained by legal reserve requirements. For some of these institutions, especially smaller ones, statutory reserve requirements might not be an important factor in their portfolio

\footnotetext{
${ }^{19}$ For weekly-reporting institutions, the data are the first reserve maintenance period that begins and ends in July of the specified year. June data are used for quarterly and annual reporters.
} 


\section{Table 2}

\section{Statistics on Legally and Economically Bound and Nonbound Depository Institutions, Selected Years}

A. Weekly Reporting Depository Institutions (Federal Reserve FR2900 report)

$\underline{1983} \quad \underline{1985} \quad \underline{1987} \quad \underline{1989}$

$\underline{1991} \underline{1993}$

$\underline{1995}$

Distribution of Reporting Depository Institutions, by reserve status (percent of reporting institutions)

\begin{tabular}{|c|c|c|c|c|c|c|c|}
\hline L-Bound & 33.7 & 33.6 & 45.4 & 47.5 & 27.4 & 34.4 & 30.2 \\
\hline L-Nonbound & 66.3 & 66.4 & 54.6 & 52.5 & 72.6 & 65.6 & 69.8 \\
\hline E-Bound & 33.7 & 33.6 & 45.4 & 47.5 & 5.9 & 6.0 & 5.5 \\
\hline E-Nonbound & 66.3 & 66.4 & 54.6 & 52.5 & 94.1 & 94.0 & 94.5 \\
\hline
\end{tabular}

Distribution of Total Deposits, by reserve status (percent of total deposits of weekly reporters)

\begin{tabular}{|c|c|c|c|c|c|c|c|}
\hline L-Bound & 60.4 & 70.3 & 79.3 & 81.6 & 72.9 & 78.2 & 75.1 \\
\hline L-Nonbound & 39.6 & 29.7 & 20.7 & 18.4 & 27.1 & 21.8 & 24.9 \\
\hline E-Bound & 60.4 & 70.3 & 79.3 & 81.6 & 54.8 & 57.7 & 56.3 \\
\hline E-Nonbound & 39.6 & 29.7 & 20.7 & 18.4 & 45.2 & 42.3 & 43.7 \\
\hline
\end{tabular}

Distribution of Net Transactions Deposits, by reserve status (percent of aggregate net transactions deposits of weekly reporters)

$\begin{array}{llllllll}\text { L-Bound } & 74.6 & 78.9 & 85.1 & 86.1 & 80.0 & 85.3 & 82.1 \\ \text { L-Nonbound } & 25.4 & 21.1 & 14.9 & 13.9 & 20.0 & 14.7 & 17.9 \\ \text { E-Bound } & 74.6 & 78.9 & 85.1 & 86.1 & 64.5 & 67.7 & 66.6 \\ \text { E-Nonbound } & 25.4 & 21.1 & 14.9 & 13.9 & 35.5 & 32.3 & 33.4\end{array}$

Distribution of Required Reserves, by reserve status (percent of aggregate required reserves of weekly reporters)

\begin{tabular}{|c|c|c|c|c|c|c|c|}
\hline L-Bound & 92.0 & 93.0 & 94.9 & 95.2 & 93.1 & 94.8 & 91.8 \\
\hline L-Nonbound & 8.0 & 7.0 & 5.1 & 4.8 & 6.9 & 5.2 & 8.2 \\
\hline E-Bound & 92.0 & 93.0 & 94.9 & 95.2 & 82.8 & 83.1 & 81.2 \\
\hline E-Nonbound & 8.0 & 7.0 & 5.1 & 4.8 & 17.2 & 16.9 & 18.8 \\
\hline
\end{tabular}

B. Statistics on the Sum of Weekly, Quarterly and Annual Reporting Depository Institutions

$\underline{1983} \quad \underline{1985} \quad \underline{1987} \quad \underline{1989} \quad \underline{1991} \quad \underline{1993} \quad \underline{1995}$

Distribution of Reporting Depository Institutions, by reserve category (percent of reporting institutions)

\begin{tabular}{|c|c|c|c|c|c|c|c|}
\hline L-Bound & 19.1 & 19.8 & 22.1 & 19.8 & 11.1 & 14.4 & 11.7 \\
\hline L-Nonbound & 80.9 & 80.2 & 77.9 & 80.2 & 88.9 & 85.6 & 88.3 \\
\hline E-Bound & 19.1 & 19.8 & 22.1 & 19.8 & 2.4 & 2.5 & 2.1 \\
\hline E-Nonbound & 80.9 & 80.2 & 77.9 & 80.2 & 97.6 & 97.5 & 97.9 \\
\hline
\end{tabular}

Distribution of Total Deposits, by reserve category (percent of reported total deposits)

\begin{tabular}{|c|c|c|c|c|c|c|}
\hline L-Bound & 56.9 & 66.8 & 73.9 & 75.5 & 67.1 & 72.1 \\
\hline L-Nonbound & 43.1 & 33.2 & 26.1 & 24.5 & 32.9 & 27.9 \\
\hline E-Bound & 56.9 & 66.8 & 73.9 & 75.5 & 50.4 & 53.2 \\
\hline E-Nonbound & 43.1 & 33.2 & 26.1 & 24.5 & 49.6 & 46.8 \\
\hline
\end{tabular}

Notation: L-Bound denotes legally bound, L-Nonbound denotes legally nonbound (applied vault cash exceeds required reserves), E-Bound denotes economically bound (as defined in this article), E-Nonbound denotes economically nonbound. All quarterly and annual reporting institutions are considered as both legally and economically nonbound in the construction of this table.

Source: tabulations by the authors from unpublished Federal Reserve data. 
decisions. In this article, we denote such economically-nonbound institutions as ENonbound, and other institutions- for which reserve requirements are binding in the traditional sense of constraining their asset portfolio choices-as E-Bound.

How might the portfolio reactions of E-Bound and E-N onbound institutions to changes in reserve-requirement ratios differ? The depository institutions' ordinary business somewhat restricts their responses. Generally, an institution must maintain adequate stocks of vault cash to convert customer deposits into currency on request, and of Federal Reserve Bank deposits to originate and absorb interbank payments. However, both constraints are somewhat flexible. There is an intraday market in vault cash, at least within larger cities, suggesting that a bank might ask a customer who is seeking a large amount of cash to wait until later in the day, when adequate currency can be obtained from the Federal Reserve or from a correspondent. Some banks require customers who are planning to withdraw a significant amount of currency to provide at least one business day's notice. It also is not uncommon for ATM machines to run out of currency. For Federal Reserve Bank deposits, there is a national secondary market, the federal funds market. For interbank payments, the Federal Reserve may delay an interbank payment if it exceeds applicable daylight or overnight overdraft limitations. Because a failure to convert a deposit into currency or to make a requested interbank payment may damage a customer relationship, a depository cannot be indifferent to its mix of vault cash and Federal Reserve Bank deposits.

The economic distinction between $\mathrm{E}$ Bound and $E-N$ onbound institutions is illustrated by the response of their excessreserve ratio to changes in reserve-requirement ratios. For E-Bound institutions, changes in reserve-requirement ratios, within the range where the requirement remains a constraint on the institutions' portfolios, will induce the institutions to match changes in required reserves with

\section{Figure 2}

\section{Surplus Vault Cash}

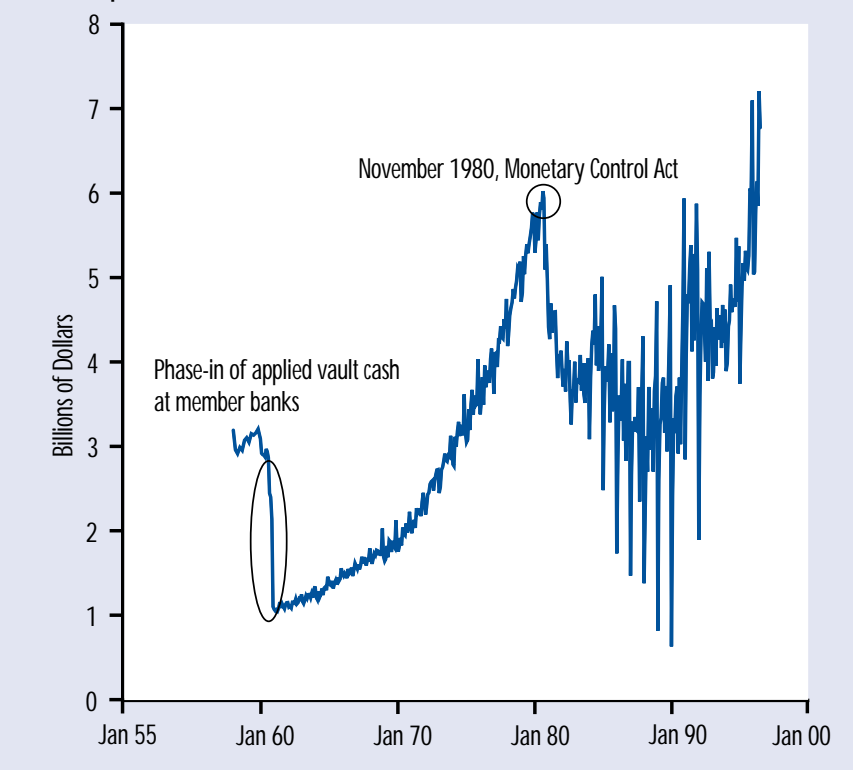

dollar-for-dollar changes in base money. As a result, excess reserves (base money held in excess of statutory requirements) will be approximately unchanged. If all depository institutions are E-Bound, then a change in reserve-requirement ratios will leave the aggregate excess reserve ratio, e, almost unaffected. The best-known historical example of this type of portfolio adjustment is member banks' reaction to the 1936-37 increase in reserve-requirement ratios. Contrary to expectations of Federal Reserve officials, member banks' excess reserve ratios did not fall sharply following the increases. ${ }^{20}$ Surplus deposits at Federal Reserve Banks, excess in the sense that they were not applied to satisfy statutory required reserves, were in fact an optimal portfolio choice by member banks; the deposits were not excess in any economic sense. The reserve-requirement ratios of 1935 were effective constraints on the banking system, with almost all member banks E-Bound.

In contrast, consider the portfolio response of E-N onbound depository institutions to a change in reserve-requirement ratios that leaves the institutions ENonbound after the change. The institu-
${ }^{20}$ See Friedman and Schwartz (1963), pp. 521-34, for a discussion of the changes in reserve requirements and documentation that the Fed anticipated that the increases in reserve-requirement ratios would substantially reduce the excess reserves of the banking system. Note that only deposits at Federal Reserve Banks were eligible to satisfy reserve requirements ( vault cash didn't become eligible until 1959). 
tions' business needs, not legal reserve ratios, are the primary determinant of their base money holdings. The excess reserves of E-N onbound institutions will vary approximately dollar-for-dollar but in the opposite direction to the change in required reserves, leaving total base money holdings largely unaffected.

The behaviors of surplus vault cash and required clearing balance contracts after the 1990-91 and 1992 changes in reserve requirement ratios suggest that a substantial proportion of depository institutions are E-N onbound. Surplus vault cash, shown in Figure 2, increased sharply in 1991 after reserve-requirement ratios were reduced to zero from 3 percent on nonpersonal time deposits and Eurodollar liabilities. This increase suggests that at least some depository institutions with surplus vault cash were E-N onbound during 1990. More dramatic perhaps was the sharp increase in required clearing balance contracts, shown in Figure 1.

Although almost all E-Bound institutions reduced their holdings of Federal Reserve Bank deposits after the reduction in reserve-requirement ratios, some found that attempts to match the reduction in their required reserves with a dollar-for-dollar decrease in their Federal Reserve deposits caused an unacceptable increase in the probability that they might experience either an overnight overdraft or exceed their regulatory cap on daylight overdrafts. ${ }^{21}$ This increase also was likely due, at least in part, to depository institutions' recognition that Federal Reserve Bank deposits no longer needed to satisfy statutory reserve requirements could be used to satisfy required clearing balance contracts. N ote that the 1991 surge in required clearing balance contracts occurred after several years of stability in the amount of such balances.

The aggregate data on required clearing balance contracts also are consistent, at least in part, with the alternative

${ }^{21}$ See Richards (1995) or Hancock and Wilcox (1996). hypothesis that some part of required clearing balances is held primarily to defray the cost of Federal Reserve priced services. Clearing balances surged during 1991 and 1992 as growth of the monetary base accelerated and the federal funds rate fell, and they decreased sharply during 1994 as growth of the base slowed and the federal funds rate rose. Although some institutions likely adjust the size of their clearing balance contracts inversely with respect to changes in the federal funds rate, the changes in 1991 seem too large to be primarily a reaction to a lower federal funds rate.

If E-N onbound institutions represent a significant share of the monetary base held by depository institutions, it is important to separate them from E-Bound institutions when measuring RAM. To make the analysis more precise, consider an economy with two distinct groups of depository institutions, both subject to Federal Reserve System reserve requirements. Define economic excess reserves as

$E R_{i}=R B_{i}-\left(r^{D} D_{i}+r^{\top} T_{i}-V C_{i}\right), i=(E B, E N)$,

where RB denotes total Federal Reserve Bank deposits held by all depository institutions (with no deduction for the amount of required clearing balance contracts), and let the subscripts EB and EN denote groups of E-Bound and E-N onbound institutions, respectively. E-Bound institutions are assumed to change the amount of base money they demand (relative to reservable deposits) approximately dollar-for-dollar following a change in statutory required reserve ratios. For this group, changes in reserve requirement ratios leave their excess reserve ratio,

$$
e_{E B}=\frac{E R_{E B}}{D^{P}},
$$

approximately unchanged. E-N onbound institutions do not change their holdings of base money (relative to reservable deposits) following a change in reserverequirement ratios. Their excess reserve ratio,

$$
e_{E N}=\frac{E R_{E N}}{D^{P}},
$$


changes in equal absolute amount, but in the opposite direction, to the reserverequirement ratio.

In the previous section, we derived the RAM adjustment proposed by Burger and Rasche (prior to passage of the M onetary Control Act) from a decomposition of the monetary base into the amounts of base money held by member banks, by other depository institutions, and by the nonbank public:

$$
\begin{aligned}
M B= & R B+C u \\
= & r^{D} D_{M}+r^{\top} T_{M}+k D^{P}+V C_{N}+ \\
& \left(V C_{M}+R B-r^{D} D_{M}-r^{\top} T_{M}\right) \\
= & {\left[r^{D} d_{M}+r^{\top} t_{M}+k+v_{N}+e_{M}\right] D^{P} . }
\end{aligned}
$$

The analysis of this section suggests that $a$ similar decomposition between E-Bound and $\mathrm{E}-\mathrm{N}$ onbound institutions would be useful for the period since implementation of the MCA. In obvious notation, the monetary base may be written as

$$
\begin{gathered}
M B=\left[r_{E B}^{D} \delta_{E B}+r_{E B}^{\top} \tau_{E B}+r_{E N}^{D} \delta_{E N}+\right. \\
\left.r_{E N}^{\top} \tau_{E N}+k+e_{E B}+e_{E N}\right] D^{P} .
\end{gathered}
$$

The appropriate RAM for inclusion in the adjusted monetary base is then

$$
R A M=\left[\left(r_{E B, 0}^{D}-r_{E B}^{D}\right) \delta_{E B}+\left(r_{E B, 0}^{T}-r_{E B}^{\top}\right) \tau_{E B}\right] D^{P},
$$

where $r_{E B, 0}^{D}$ and $r_{E B, 0}^{\top}$ denote the statutory reserve-requirement ratios on demand and time deposits, respectively, during the base period of the RAM adjustment. ${ }^{22} \mathrm{~N}$ ote that this RAM includes only deposits at E-Bound institutions. In all essential aspects, the treatment of $\mathrm{E}-\mathrm{N}$ onbound institutions in this RAM is analogous to the treatment of nonmember banks in Burger and Rasche (1977).

The adjusted monetary base may be written as

$$
\begin{aligned}
\mathrm{AMB}= & \mathrm{MB}+\mathrm{RAM} \\
= & {\left[\mathrm{r}_{\mathrm{EB}, 0}^{\mathrm{D}} \delta_{\mathrm{EB}}+\mathrm{r}_{\mathrm{EB}, 0}^{\top} \tau_{\mathrm{EB}}+\mathrm{r}_{\mathrm{EN}}^{\mathrm{D}} \delta_{\mathrm{EN}}+\right.} \\
& \left.r_{\mathrm{EN}}^{\top} \tau_{\mathrm{EN}}+\mathrm{k}+\mathrm{e}_{\mathrm{EB}}+\mathrm{e}_{\mathrm{EN}}\right] \mathrm{D}^{\mathrm{P} .}
\end{aligned}
$$

The adjusted monetary base multiplier is

$$
\begin{gathered}
\frac{M 1}{A M B}= \\
\frac{1+k}{\left(r_{E B, 0}^{D} \delta_{E B}+r_{E B, 0}^{\top} \tau_{E B}+e_{E B}\right)+\left(r_{E N}^{D} \delta_{E N}+r_{E N}^{\top} \tau_{E N}+e_{E N}\right)} .
\end{gathered}
$$

By assumption, $e_{E B}$ does not change when $r_{E B, 0}^{D}$ or $r_{E B, 0}^{\top}$ changes because E-Bound institutions match reductions in their required reserves due to changes in statutory reserve-requirement ratios about dollar-for-dollar with reductions in their holdings of base money. In contrast, $e_{E N}$ is assumed to change when $r_{E N}^{D}$ or $r_{E N}^{\top}$ changes so as to leave the second term in the denominator $\left(\mathrm{r}_{\mathrm{EN}}^{\mathrm{D}} \delta_{\mathrm{EN}}+\mathrm{r}_{\mathrm{EN}}^{\top} \tau_{\mathrm{EN}}+\mathrm{e}_{\mathrm{EN}}\right)$ unchanged.

To measure accurately this post-M onetary Control Act RAM, it is necessary to determine the time-varying fractions of transaction deposits, $\delta_{\mathrm{EB}}$, and time deposits, $\tau_{\mathrm{EB}}$, at E-Bound depository institutions. These fractions cannot be identified in aggregate data; they must be obtained from data on individual financial institutions. Later in this article we present a statistical analysis of individual bank data that allows us to develop criteria for separating E-Bound and E-N onbound institutions. Some of the results of that analysis are shown in Figures 3 and 4, and in Table 2. The estimated number of E-Bound depository institutions, shown in Figure 3, fell by 80 percent, to about 500 institutions, following the 1990-91 reduction in reserve requirements.

The proportions of transaction and nontransaction deposits at E-Bound institutions, shown in Figure 4, fell from peaks in 1990 to approximately 65 and 54 percent, respectively, following the 1990-91 reduction in reserve requirements. (Recall that the reserve-requirement ratio on time and savings deposits was reduced to zero in December 1990.) The rows labeled ENonbound and E-Bound in Table 2 show additional data. In 1995, we estimate that only about 2 percent of U.S. depository institutions were E-Bound- that is, found statutory reserve requirements to be an important determinant of their business decisions. Only deposits at these E-Bound

\footnotetext{
${ }^{22}$ The new St. Louis adjusted monetary base incorporates four RAM adjustments, each built using a different base period.
} 


\section{Figure 3}

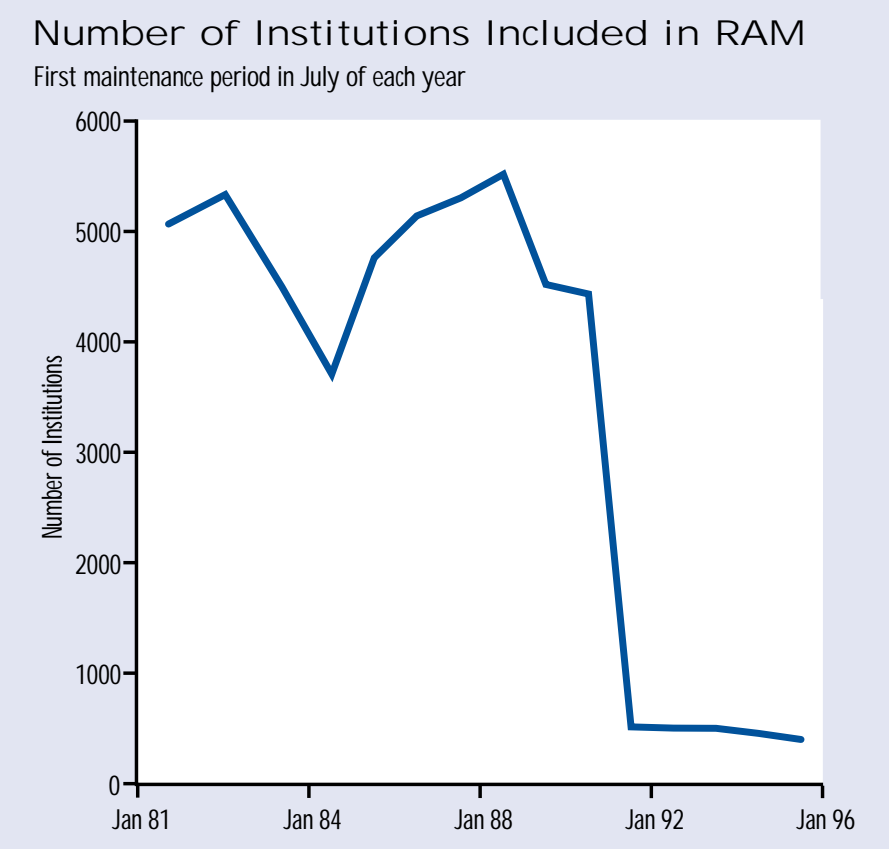

Figure 4

\section{Proportions of Deposits in Economically}

First maintenance period in July of each year

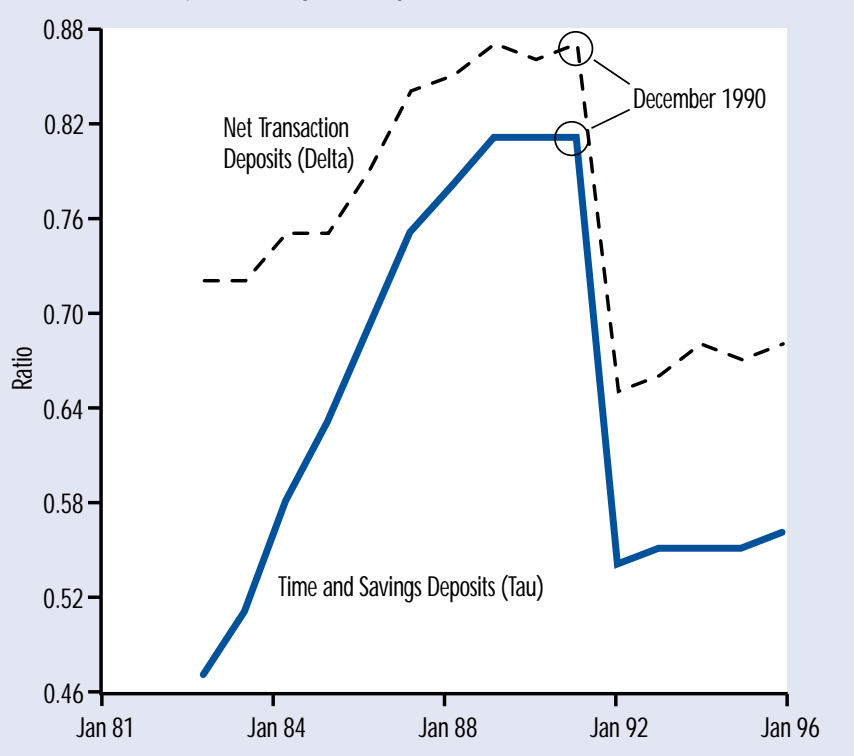

institutions are included in the new RAM adjustment for the St. Louis adjusted monetary base (see Anderson and Rasche, 1996a).
Time Deposit Ratios and Reserve Requirement Changes

Our discussion of RAM has focused to this point on the direct impact of changes in reserve-requirement ratios on the monetary base multiplier, assuming that the other ratios in the adjusted monetary base multipliers for $\mathrm{M} 1$ and $\mathrm{M} 2$ are unaffected by changes in the reserve requirement ratios, or that

$$
\frac{d m}{d r}=\frac{\partial m}{\partial r}=-\left(\frac{m}{r+e+k}\right)
$$

In the previous section, we showed how, for E-N onbound institutions, the excess reserve ratio, e, might be a function of $r$. In this subsection, we explore whether the time deposit ratio, $t$, might be a function of $r$.

The end of Regulation Q ceilings on deposit offering rates during the early 1980s gave depository institutions a tool, changes in deposit offering rates, that could in principle be used to adjust their reserve positions by inducing customers to shift among categories of deposits with different reserve-requirement ratios. In a competitive market without legal interest rate ceilings, it seems reasonable to expect that changes in reserve-requirement ratios will affect the rates offered by E-Bound institutions on different types of deposits. Further, it seems reasonable that economic agents will base decisions about the proportion of their wealth to hold in the form of time deposits, in part, on the rates of return offered on time deposits. If so, following implementation of the M onetary Control Act, competitive pressures may have caused increases in offering rates on savings and time deposits, relative to those on transaction deposits. Similarly, the December 1990-January 1991 reduction to zero of reserve requirements on nonpersonal time deposits may have increased offering rates on large negotiable CDs relative to other instruments. Both events may have increased the ratio of time deposits to transaction deposits at E-Bound institutions, $\tau_{\mathrm{EB}}$, that enters the adjusted monetary base multiplier. ${ }^{23}$ 
Rate Spreads on 3-Month Instruments

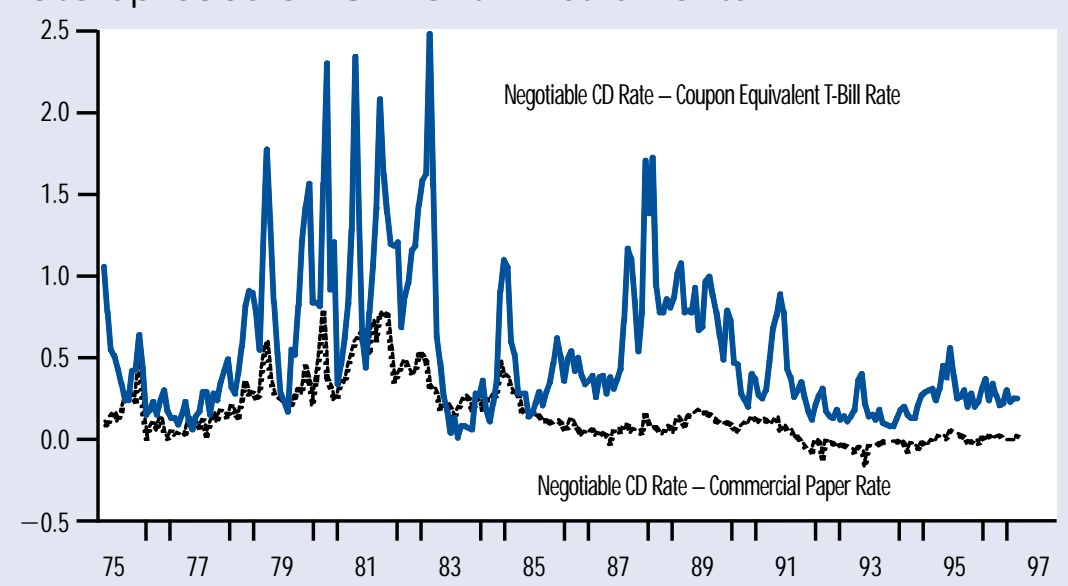

Rate Spreads on 6-Month Instruments

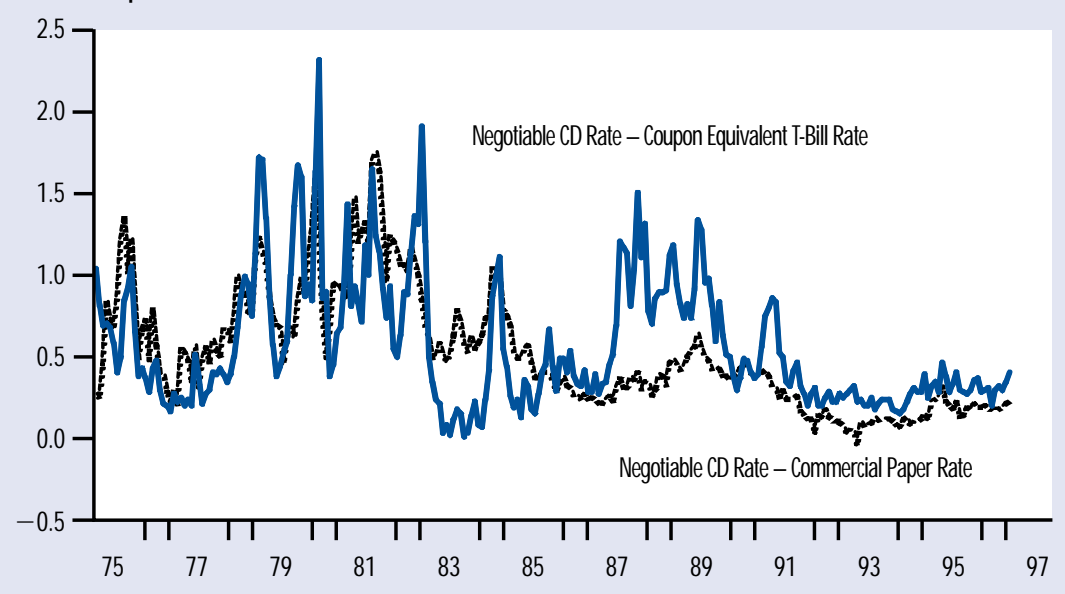

Testing for a shift in the time deposit ratio circa 1980 is difficult, due to Regulation $\mathrm{Q}$ controls. Data from the latter period (1990-91) suggest, however, that banks do not alter their offering rates in response to substantial changes in reserve requirements. The spreads between rates on large negotiable CDs and on Treasury bills and commercial paper are shown in Figure 5. Although there is considerable variability from week to week, there is no discernible trend. The spread of CD rates over threeand six-month Treasury bill rates fluctuates around 50 basis points; the spread of $C D$ rates over commercial paper rates fluctuates around zero. N either has any discernible spikes or shifts at the beginning of 1991 when the reserve-requirement ratio was reduced to zero on nonpersonal time deposits. Hence, we do not include in RAM any adjustment for potential indirect effects of reserve-requirement ratio changes on the multiplier via changes in the timedeposit ratio at E-Bound institutions.

\section{MICROECONOMIC} EVIDENCE: ARE BANKS BOUND BY RESERVE REQUIREMENTS?

In this section, the reactions of commercial banks to the December 1990-January 1991 and A pril 1992 reductions in reserve requirement ratios are
${ }^{23}$ The multiplier discussed here is for transaction money, M1. Multipliers for the broader measures of money such as zeromaturity money $(M z M), M 2$, and M3 include additional terms in their numerators which, in a more detailed analysis, would be shown as components of the time deposit ratio, t. For examples, see Rasche and Johannes (1985). 
examined in an analysis of variance (AN OVA) framework. ${ }^{24}$ The analysis seeks to quantify the different reactions of $L$ Bound and L-N onbound banks, of various sizes, to changes in statutory reserverequirement ratios. The goal of the analysis is to develop criteria that distinguish E-Bound from E-N onbound institutions, consistent with the construction of RAM outlined above. Our data sample consists of commercial banks that reported weekly deposit and reserve levels to the Federal Reserve from mid-1990 through the end of 1992.

To this point in this article, the terms bound ( $L$-Bound) and nonbound ( $L$ Nonbound) have described the reserve position of an individual bank during a single reserve maintenance period. (Recall that a bank is said to be L-N onbound if it fully satisfies its required reserves with vault cash.) In this section, we use these terms more broadly. For tractability in statistical analysis, we classify individual banks as being either of type L-Bound or type L-N onbound according to a specified criterion applied to the bank during a number of reserve maintenance periods. This classification system would be trivial if all institutions, during all reserve maintenance periods, were either L-Bound or L-N onbound and did not change status. In fact, small and medium size institutions often change categories, being L-N onbound in periods when retail cash demands are heavy and L-Bound in others; larger banks tend to remain consistently in one category.

In our analysis, we examined three

${ }^{24}$ Because of the unsettled state of the thritt industry during this period, we exclude thrifts from the analysis.

25 The Gam-St. Germain Act of 1982 created the reserve exemption amount, which is subject to a zero reserve requirement. Originally $\$ 2.1$ million of deposits, it also is indexed. See Anderson and Kavajec (1994) or the Federal Reserve System's Regulation D, Reserve Requirements, for details.
$3,4,5$, and 6 show comparative results based on cases (1) and (3), respectively.

Our size groupings are broadly consistent with categories used in other banking studies. Banks classified as L-Bound are subsequently separated into four size classes-small, medium, regional and large - based on net transaction deposits, while L-N onbound banks are separated into only two: small and medium. There are too few larger L-N onbound banks for analysis. The Monetary Control Act of 1980 established a tiered system of reserve requirements wherein the first $\$ 25$ million of net transaction deposits, the "low reserve tranche," was subject to a 3 percent requirement, while larger amounts were subject to a 12 percent requirement. Initially set at $\$ 25$ million, the low reserve tranche is indexed annually to the change in the aggregate amount of net transaction deposits. We classify banks in our sample data as small if their holdings of net transaction deposits did not exceed the low reserve tranche during any reserve maintenance period in the second half of 1990 (the low reserve tranche was $\$ 41.1$ million in 1990). ${ }^{25}$ We classify banks as medium-sized if their average level of net transaction deposits during the second half of 1990 was greater than the low reserve tranche but less than $\$ 135$ million, as regional-sized if their net transaction deposits averaged more than $\$ 135$ million but less than $\$ 500$ million, and as large if their net transaction deposits averaged more than $\$ 500$ million.

Statistical inferences regarding banks' reactions to reserve-requirement changes are robust to reasonable alternative sizeclassification schemes. Use of the low reserve tranche for delineating small banks provides an important control in our analysis, because the A pril 1992 change in reserve-requirement ratios affected only banks with transaction deposits above the tranche. Results for the medium and regional groups are not sensitive to the precise cut-off selected to separate the groups because there are relatively few banks with net transaction deposits between about $\$ 100$ to $\$ 150$ million. The $\$ 500$ million cut-off places about 150 
banks in our large category, similar to the group of large weekly reporting banks on the list published by the Federal Reserve. ${ }^{26}$ The estimated models shown below al so are not sensitive to inclusion or exclusion of banks that acquired other institutions.

Summarizing our results, we find that:

- L-N onbound banks did not change their holdings of base money (vault cash plus F ederal Reserve Bank deposits), relative to transaction deposits, when reserve requirements changed in 1990-91 or 1992.

These banks chose to hold enough vault cash to satisfy their reserve requirements. If vault cash is held primarily to convert deposits into currency on request, then their holdings of vault cash are likely to be insensitive to changes in statutory reserve requirements. The quantity of Federal Reserve Bank deposits held by these banks, if any, is unlikely to be affected by changes in statutory reserve requirements because the deposits are not being held to satisfy reserve requirements.

- Small and medium-sized L-Bound banks changed their holdings of base money somewhat in response to the 1990-91 reduction of the reserve-requirement ratio on time and savings deposits to zero from 3 percent, but they did not respond to the 1992 reduction of the reserve requirement ratio on net transaction deposits to 10 percent from 12 percent.

Small L-Bound institutions primarily differ from small L-N onbound institutions by choosing to hold less vault cash; the two groups of banks have similar mixtures of deposits. In the absence of a fully worked out model of bank reserve management, it is difficult to identify factors that might account for the differing responses of small L-N onbound and small L-Bound to the 1990-91 changes in reserve-requirement ratios. In contrast, the 1992 reduction in the reserve-requirement ratio on net transaction deposits affected (algebraically) only larger institutions with net transaction deposits above approximately $\$ 42$ million. The reduction had no effect on banks subject to only a 3 percent marginal reserve requirement, and only a weak effect on medium-sized banks that faced a 12 percent requirement on only a part of their transaction deposits.

- Larger L-Bound banks responded strongly to the 1990-91 reduction and somewhat less strongly to the 1992 reduction.

These banks chose to satisfy their required reserves by holding relatively large amounts of Federal Reserve Bank deposits. In general, these amounts are more than what is necessary for the banks' paymentsrelated activities, such as check clearing and wire transfer. If statutory reserve requirements are binding for any group of banks, it must be for these.

Our models seek to estimate the response of banks' base money holdings to changes in reserve requirements.

Measuring the amount of base money held by some nonmember institutions is problematic, however. While all banks in our data report their daily holdings of vault cash to the Federal Reserve, some nonmember banks do not hold Federal Reserve deposits in their own name; rather, they hold them indirectly via a passthrough contract with a correspondent bank. ${ }^{27}$ In addition, some nonmember banks hold Federal Reserve deposits both indirectly (through a correspondent) and directly (in their own account). We increased the Federal Reserve deposits reported by banks with passthrough reserve arrangements by an amount equal to the difference between the bank's required reserves and its applied vault cash. At the same time, we reduced each correspondent bank's reported Federal Reserve deposits by the amount of its respondent banks' required reserves charged against the correspondent's Federal Reserve account. Given the data reported by banks to the Federal Reserve, this is the only feasible method for measuring the amount of Federal Reserve deposits held (indirectly) by banks with passthrough reserve contracts.

Summary statistics for our sample of banks are shown in Table 3. The sample consists of commercial banks that reported
${ }^{26}$ See Table 1.27 in the Federal Reserve Bulletin.

${ }^{27}$ Nonmember depository institutions may contract with the Federal Reserve to satisfy their required reserves (beyond vault cash) by having the amount of the requirement charged against the Federal Reserve deposit account of an eligible correspondent institution (a socalled "passthrough" reserve contract). Nonmember institutions that satisfy required reserves via passthrough contract may open an additional Federal Reserve account in their own name. Federal Reserve deposits in this second account may be used to satisfy a required clearing balance contract but may not be used to satisfy required reserves. (of course, the funds could be loaned via the federal funds market to the correspondent.) 
${ }^{28}$ Our sample may underrepresent small depository institutions that are not required to report data weekly to the Federal Reserve. We assume that virtually all of these institutions would be classified as economically nonbound and excluded from the calculation of RAM. For a discussion of Federal Reserve data reporting requirements, see Anderson and Kavajecz (1994).

${ }^{29}$ Banks that acquire other depository institutions are permitted under the Federal Reserve's Regulation $D$ to phase out, during the following eight quarters, the benefit of the acquired institution's low reserve tranche. All banks involved in such acquisitions are excluded from our statistical analysis. Such banks are included in the calculation of RAM, where we allow for this effect by adjusting the size of the tranche loss adjustment to reflect the size of the tranche in the base period, January 7, 1991; see Anderson and Rasche (1996a).

${ }^{30}$ The overall sample size also is smaller in Part B because 13 regional and large L-Bound banks in Part A are reclassified as L-Nonbound in Part B, and dropped from the analysis.

${ }^{31}$ In December 1995, for example, required reserves of all depositories were $\$ 56.6$ billion, of which $\$ 37.5$ billion was satisfied with vault cash. See for example Aggregate Reserves of Depository Institutions and the Monetary Base, Board of Governors' weekly statistical release (H.3), April 25, 1996, Table 2. data weekly to the Federal Reserve from mid-1990 through the end of 1992. ${ }^{28}$ Banks without data for all included reserve maintenance periods are omitted, as are banks involved in mergers or acquisitions. ${ }^{29}$ Part $A$ and Part $B$ of the table show banks classified as L-Bound and L-N onbound via two alternative schemes. In Part A, banks are classified as L-Bound if they were L-Bound in $1992 \mathrm{H2}$, after both the 1990-91 and 1992 reductions in reserve requirements; banks not classified as LBound are classified as L-N onbound, even if they were bound during some reserve maintenance periods in 1990 and 1991. In Part B, banks are classified as L-Bound if and only if they were L-Bound in every reserve maintenance period during 1990 $\mathrm{H} 2,1991 \mathrm{H} 2$ and $1992 \mathrm{H} 2$; otherwise, they are classified as L-N onbound. Application of the latter criteria reduces the number of L-Bound banks from 1822 in part A to 710 in part $B$, primarily by pushing banks that are close to being L-N onbound (or in other words, they hold enough vault cash to fully satisfy their required reserves in some maintenance periods) from the $L$ Bound group in part A into the L-N onbound group in part $B .{ }^{30}$

Part A of Table 3 shows that the 1990 91 reduction in reserve requirements on nonpersonal time and savings deposits reduced required reserves at small, medium, regional and large banks by about 44 percent, 19 percent, 17 percent and 18 percent, respectively, after allowing for increases in their net transactions deposits. On average, these banks satisfied about one-half of their required reserves with vault cash (column 4). ${ }^{31}$ Contracted clearing balances increased sharply from 1990 to 1992, approximately doubling for the smallest banks and increasing by almost an order of magnitude for large banks.

\section{A Traditional Fixed Effects ANO VA Model}

In Table 4 (see page $\bullet \bullet$ ), we present traditional ANOVA fixed-effects regression estimates for the effects of changes in reserve requirements in 1990-91 and 1992 on the ratio $\left\{\frac{\text { vault cash }+F \text { ederal } \text { Reserve deposits }}{\text { net transactions deposits }}\right\}$

during the last 13 reserve maintenance periods in 1990, 1991 and 1992, a total of 39 observations on each bank. The model is

$$
\begin{gathered}
\mathrm{y}_{\mathrm{ijt}}=\phi+\sum_{\mathrm{i}=1}^{\mathrm{N}-1}\left(\alpha_{\mathrm{i}}-\alpha_{\mathrm{N}}\right) \mathrm{D}_{\mathrm{ijt}}^{\mathrm{B}}+ \\
\sum_{\mathrm{t}=90}^{91}\left(\lambda_{\mathrm{t}}-\lambda_{92}\right) \mathrm{D}_{\mathrm{ijt}}^{\mathrm{Y}}+\sum_{\mathrm{j}=1}^{12}\left(\gamma_{\mathrm{j}}-\gamma_{13}\right) \mathrm{D}_{\mathrm{ijt}}^{\mathrm{P}}+ \\
\xi \mathrm{D}_{\mathrm{ijt}}^{\mathrm{R}}+\varepsilon_{\mathrm{ijt}},
\end{gathered}
$$

where

$y_{\mathrm{ijt}}=$ the ratio of base money (vault cash plus deposits at Federal Reserve Banks) to net transaction deposits held by bank $i$ in maintenance period $j$ in year $t$, $(i=1, \ldots, N),(j=1, \ldots, 13),(t=90, \ldots, 92)$. $D_{\mathrm{ijt}}^{\mathrm{B}}=1$ for bank $\mathrm{i}$, and 0 otherwise, $D_{i j t}^{Y}=1$ in year $t$, and 0 otherwise, $D_{i j t}^{P}=1$ in maintenance period $\mathrm{j}$, and 0 otherwise,

$D_{i j t}^{R}=1$ if bank $i$ had a clearing balance contract in maintenance period $\mathrm{j}$ of year $t$, and $\varepsilon_{i j t}$ is an assumed i.i.d. disturbance.

The dummy variables $D_{\mathrm{ijt}}^{\mathrm{p}}$ index the relative position of reserve maintenance period $\mathrm{j}$ within the year, with the first period in July of each year numbered " 1 " and the last period of the year numbered "13". As such, they absorb seasonal fluctuations that may differ in strength across banks. We interpret the $D_{\mathrm{ijt}}^{Y}$ as representing the effects of changes in reserve requirements between 1990, 1991, and 1992, although as dummy variables they may also pick up other year-specific effects. Estimates presented in Parts A and $B$ of Table 4 correspond to the statistics shown in Parts $A$ and $B$ of Table 3. Because the estimates in Parts $A$ and $B$ are similar, we discuss only the estimates shown in Part A. Standard errors reported in the table are Huber-W hite robust estimates of the regression covariance matrix.

For all groups of banks, the null hypothesis of no significant year effects in 
Table 3

\section{Summary Statistics for Commercial Banks Used in ANOVA}

(by reserve status and size, billions of dollars except number of institutions)

\section{A. Classified by Legal Reserve Status in 1992 and by Size in $1990^{1}$}

Amount of

Base Money

Held

(Vault Cash

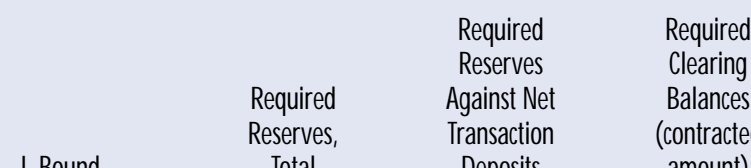

amount)

Applied Vault

Aggregate

Net

L-Bound

Total

Deposits

Cash

Transaction

Deposits

+ Federal

Reserve

Bank

Deposits)

Number of

Banks

\section{0}

Small

1.16

0.62

0.11

0.68

24.3

1.37

1139

Medium

2.67

2.04

0.14

1.37

33.0

2.89

512

Regional

3.41

2.81

1.37

27.4

3.57

8.86

122

0.10

3.64

61.1

49

1991

Small

Medium

0.72

0.72

0.17

0.61

26.9

1139

Regional

2.34

2.34

0.20

1.38

35.7

1.09

512

Large

7.41

7.41

0.16

1.40

29.6

2.64

122

63.6

3.28

7.83

49

1992

Small

Medium

0.94

0.94

0.21

0.70

31.8

1.30

1139

Regional

2.56

2.56

0.26

1.47

41.3

2.89

512

Large

7.08

3.06

0.35

1.43

34.4

3.46

122

0.89

3.55

72.4

8.01

49

L-Nonbound

1990

Small

Medium

1.45

0.85

0.21

1.33

35.78

2.33

2209

0.14

0.10

0.13

2.27

0.19

45

1991

Small

Medium

0.93

0.93

0.25

0.93

38.37

2.33

2209

0.11

0.11

0.02

0.10

2.29

0.18

45

1992

Small

Medium

1.08

1.08

0.30

1.08

43.35

2.48

2209

0.11

0.11

2.46

0.20

${ }^{1}$ Classifications are based on banks' legal reserve status in $1992 \mathrm{H} 2$ and on their size in $1990 \mathrm{H} 2$. Banks are classified as L-Bound if they were legally bound in one or more reserve maintenance periods during $1992 \mathrm{H2}$; if not, they are classified as L-Nonbound. Banks are classified as small if their net transaction deposits did not exceed the low reserve tranche ( $\$ 40.4$ million) in any reserve maintenance period during $1990 \mathrm{H} 2$, and are classified as medium or regional if their average level of net transaction deposits during $1990 \mathrm{H} 2$ did not exceed $\$ 125$ million or $\$ 500$ million, respectively. Banks with net transaction deposits averaging more than $\$ 500$ million during 1990 H2 are classified as large. 
Table 3 , continued

\section{Summary Statistics for Commercial Banks Used in ANOVA}

(by reserve status and size, billions of dollars except number of institutions)

B. Classified by Legal Reserve Status in 1990, 1991 and 1992, and by Size in $1990^{2}$

\begin{tabular}{|c|c|c|c|c|c|c|c|}
\hline L-Bound & $\begin{array}{c}\text { Required } \\
\text { Reserves, } \\
\text { Total }\end{array}$ & $\begin{array}{c}\text { Required } \\
\text { Reserves } \\
\text { Against Net } \\
\text { Transaction } \\
\text { Deposits }\end{array}$ & $\begin{array}{c}\text { Required } \\
\text { Clearing } \\
\text { Balances } \\
\text { (contracted } \\
\text { amount) }\end{array}$ & $\begin{array}{l}\text { Applied Vault } \\
\text { Cash }\end{array}$ & $\begin{array}{l}\text { Aggregate } \\
\text { Net } \\
\text { Transaction } \\
\text { Deposits }\end{array}$ & $\begin{array}{l}\text { Base Money } \\
\text { Held } \\
\text { (Vault Cash } \\
\text { + Federal } \\
\text { Reserve } \\
\text { Bank } \\
\text { Deposits) }\end{array}$ & $\begin{array}{c}\text { Number of } \\
\text { Banks }\end{array}$ \\
\hline \multicolumn{8}{|l|}{1990} \\
\hline Small & 0.33 & 0.14 & 0.02 & 0.09 & 5.5 & 0.36 & 236 \\
\hline Medium & 1.95 & 1.52 & 0.09 & 0.82 & 22.5 & 2.06 & 316 \\
\hline Regional & 3.15 & 2.61 & 0.12 & 1.17 & 25.3 & 3.30 & 114 \\
\hline Large & 8.10 & 6.61 & 0.09 & 3.28 & 56.7 & 8.26 & 44 \\
\hline \multicolumn{8}{|l|}{1991} \\
\hline Small & 0.18 & 0.18 & 0.03 & 0.09 & 6.2 & 0.25 & 236 \\
\hline Medium & 1.73 & 1.73 & 0.11 & 0.85 & 24.4 & 1.87 & 316 \\
\hline Regional & 2.86 & 2.86 & 0.15 & 1.22 & 27.5 & 3.04 & 114 \\
\hline Large & 6.87 & 6.87 & 0.34 & 3.24 & 58.9 & 7.27 & 44 \\
\hline \multicolumn{8}{|l|}{1992} \\
\hline Small & 0.24 & 0.24 & 0.04 & 0.10 & 7.5 & 0.32 & 236 \\
\hline Medium & 1.86 & 1.86 & 0.15 & 0.89 & 28.3 & 2.05 & 316 \\
\hline Regional & 2.84 & 2.84 & 0.34 & 1.25 & 31.9 & 3.21 & 114 \\
\hline Large & 6.64 & 6.64 & 0.86 & 3.21 & 67.9 & 7.53 & 44 \\
\hline \multicolumn{8}{|c|}{$\underline{\text { L-Nonbound }}$} \\
\hline \multicolumn{8}{|l|}{1990} \\
\hline Small & 2.28 & 1.32 & 0.30 & 1.92 & 54.6 & 3.34 & 3112 \\
\hline Medium & 0.86 & 0.63 & 0.75 & 0.67 & 12.8 & 1.01 & 241 \\
\hline \multicolumn{8}{|l|}{1991} \\
\hline Small & 1.47 & 1.47 & 0.38 & 1.44 & 59.0 & 3.18 & 3112 \\
\hline Medium & 0.72 & 0.72 & 0.11 & 0.63 & 13.6 & 0.96 & 241 \\
\hline \multicolumn{8}{|l|}{1992} \\
\hline Small & 1.77 & 1.77 & 0.47 & 1.67 & 67.7 & 3.46 & 3112 \\
\hline Medium & 0.81 & 0.81 & 0.13 & 0.69 & 15.4 & 1.04 & 241 \\
\hline
\end{tabular}




\section{ANOVA Model Estimates for Weekly-Reporting Banks}

L-Bound Banks

Statistic

Statistic

\section{A. Classified on Legal Reserve Status in 1992 and on Size in $1990^{1}$}

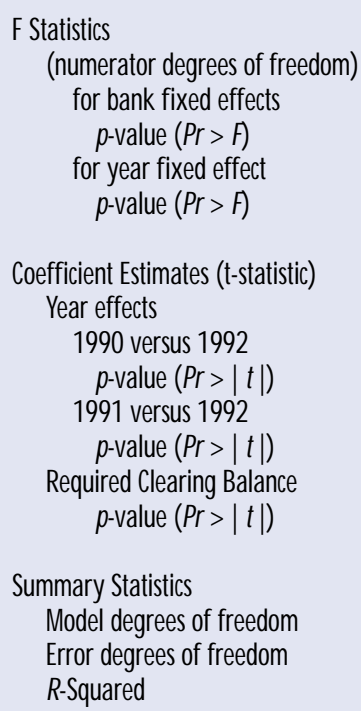

$72.4(121)$
0.0001
$346.4(2)$
0.0001


$0.032(26.5)$
0.0001
$0.013(10.5)$
0.0001
$0.022(6.8)$
0.0001

136
4621
0.67

\begin{tabular}{|c|c|c|}
\hline & & \\
\hline $69.0(48)$ & $119.7(2208)$ & $144.7(44)$ \\
\hline 0.0001 & 0.0001 & 0.0001 \\
\hline $1152.5(2)$ & $2781.9(2)$ & $10.4(2)$ \\
\hline 0.0001 & 0.0001 & 0.0001 \\
& & \\
& & \\
\hline $0.036(47.9)$ & $0.009(75.1)$ & $0.003(4.0)$ \\
\hline 0.0001 & 0.0001 & 0.0001 \\
$0.013(17.4)$ & $0.003(30.7)$ & $0.0(0.0)$ \\
\hline 0.0001 & 0.0001 & 0.9978 \\
$0.015(11.3)$ & $0.009(26.9)$ & $0.001(0.4)$ \\
\hline 0.0001 & 0.0001 & 0.6756 \\
& & \\
\hline 63 & 2223 & 59 \\
\hline 1847 & 83927 & 1695 \\
0.75 & 0.76 & 0.79 \\
\hline
\end{tabular}

B. Classified on Legal Reserve Status in 1990, 1991 and 1992, and on Size in $1990^{2}$

\begin{tabular}{|c|c|c|c|c|c|c|}
\hline \\
\hline $\begin{array}{l}\text { F Statistics } \\
\text { (numerator degrees of freedom) } \\
\text { for bank fixed effects } \\
p \text {-value ( } P r>F) \\
\text { for year fixed effect } \\
p \text {-value ( } P r>F)\end{array}$ & $\begin{array}{c}47.4(235) \\
0.0001 \\
426.7(2) \\
0.0001\end{array}$ & $\begin{array}{c}85.6(315) \\
0.0001 \\
2786.0(2) \\
0.0001\end{array}$ & $\begin{array}{c}73.0(113) \\
0.0001 \\
305.9(2) \\
0.0001\end{array}$ & $\begin{array}{r}75.5(43) \\
0.0001 \\
1040.7(2) \\
0.0001\end{array}$ & $\begin{array}{c}32.2(3111) \\
0.0001 \\
825.9(2) \\
0.0001\end{array}$ & $\begin{array}{c}131.1(240) \\
0.0001 \\
965.8(2) \\
0.0001\end{array}$ \\
\hline \multicolumn{7}{|l|}{$\begin{array}{l}\text { Coefficient Estimates (t-statistic) } \\
\text { Year effects }\end{array}$} \\
\hline $\begin{array}{c}1990 \text { versus } 1992 \\
p \text {-value }(\operatorname{Pr}>|t|) \\
1991 \text { versus } 1992 \\
p \text {-value }(\operatorname{Pr}>|t|) \\
\text { Required Clearing Balance } \\
\quad p \text {-value }(\operatorname{Pr}>|t|)\end{array}$ & $\begin{array}{l}0.029(24.3) \\
0.0001 \\
-0.002(1.9) \\
0.0612 \\
-0.004(1.1) \\
0.2631\end{array}$ & $\begin{array}{l}0.019(70.6) \\
0.0001 \\
0.004(14.4) \\
0.0001 \\
0.006(6.9) \\
0.0001\end{array}$ & $\begin{array}{l}0.032(24.6) \\
0.0001 \\
0.013(10.0) \\
0.0001 \\
0.030(7.4) \\
0.0001\end{array}$ & $\begin{array}{l}0.037(44.8) \\
0.0001 \\
0.012(15.5) \\
0.0001 \\
0.015(11.3) \\
0.0001\end{array}$ & $\begin{array}{l}0.012(39.0) \\
0.0001 \\
0.003(9.7) \\
0.0001 \\
0.007(8.8) \\
0.0001\end{array}$ & $\begin{array}{l}0.011(41.6) \\
0.0001 \\
0.002(8.4) \\
0.0001 \\
0.004(4.7) \\
0.0001\end{array}$ \\
\hline $\begin{array}{l}\text { Summary Statistics } \\
\text { Model degrees of freedom } \\
\text { Error degrees of freedom } \\
\text { R-Squared }\end{array}$ & $\begin{array}{c}250 \\
8953 \\
0.57\end{array}$ & $\begin{array}{l}330 \\
11993 \\
0.73\end{array}$ & $\begin{array}{c}128 \\
4317 \\
0.67\end{array}$ & $\begin{array}{c}58 \\
1657 \\
0.76\end{array}$ & $\begin{array}{l}3126 \\
118241 \\
0.46\end{array}$ & $\begin{array}{l}255 \\
9143 \\
0.79\end{array}$ \\
\hline \multicolumn{7}{|c|}{$\begin{array}{l}\text { Banks are classified as L-Bound if they were legally bound in one or more reserve maintenance periods during } 1992 \mathrm{H2} \text {; if not, they are dassified as L-Nonbound. } \\
\text { Banks are classified as small if their net transaction deposits did not exceed the low reserve tranche ( } \$ 40.4 \text { million) in any reserve maintenance period during } \\
1990 \mathrm{H2} \text {, and are classified as medium or regional if their average level of net transaction deposits during } 1990 \mathrm{H} 2 \text { did not exceed } \$ 125 \text { million or } \$ 500 \text { million, } \\
\text { respectively. Banks with net transaction deposits averaging more than } \$ 500 \text { million during } 1990 \mathrm{H} 2 \text { are classified as large. }\end{array}$} \\
\hline
\end{tabular}


the behavior of $y_{i j t}$ is rejected. Consider, then, the regression results for each group of banks:

Small L-Bound banks. The model estimates suggest a strong response by small L-Bound banks to the 1990-91 reduction in reserve requirements. The reasonableness of the estimated ANOVA regression coefficients can be judged by comparing them to estimates calculated from the summary statistics shown in Table 3, under the null hypothesis that the banks are E-Bound- that is, that the banks' reductions in their holdings of base money will match, dollar-for-dollar, the decrease in their required reserves. Approximately half of the required reserves of these banks in 1990 was due to net transaction deposits ( $\$ 620$ million), and about half was due to nontransaction deposits. Each category of deposits was subject to a 3 percent marginal requirement. Ignoring the zero reserve requirement on the reserve exemption amount, the reduction to zero of the reserve-requirement ratio on nonpersonal time and savings deposits might reduce the banks' average ratio of base money to net transaction deposits by about one-half of its 1990 value of 0.056 , or 0.028. The estimated AN OVA effect equals the estimated coefficient on the 1990 year dummy variable less the coefficient on the 1991 year dummy variable, or

$$
\left(\hat{\lambda}_{90}-\hat{\lambda}_{91}\right)=0.021-0.001=0.02 \text {. }
$$

Both $\hat{\lambda}_{90}$ and $\hat{\lambda}_{91}$ are estimated relative to 1992 because $D_{i i, 92}^{Y}$ is omitted from the regression. The size of ANOVA effect is close to, but slightly smaller than, the effect calculated from the summary statistics.

The regression coefficient for 1991, $\hat{\lambda}_{91}$, measures small L-Bound banks' reaction to the April 1992 reduction in the marginal reserve requirement on net transaction deposits to10 percent from 12 percent. Because these banks' net transaction deposits were below the low reserve tranche, their required reserves were unaffected by the change. The estimated AN OVA effect, 0.0006 , is about zero, as expected.
Medium L-Bound Banks. The results for medium-sized L-Bound banks are similar to those for small L-Bound banks. As above, we can judge the reasonableness of the estimated AN OVA effect by calculating a preliminary estimate from the summary statistics in Table 3, under the null hypothesis that the banks are E-Bound both before and after the change in the legal requirements. About three-fourths of the required reserves of these banks were due to net transaction deposits in 1990, and their total required reserves averaged about 8.1 percent of their net transaction deposits. Thus, reducing to zero the reserve requirement on nonpersonal time and savings deposits seems likely to reduce by about one-fourth their overall ratio of required reserves and base money holdings relative to net transaction deposits, a decrease of about 0.02 .

The estimated ANOVA effect of the 1990 reduction equals the coefficient on the 1990 year dummy less the coefficient on the 1991 year dummy variable, or

$$
\left(\hat{\lambda}_{90}-\hat{\lambda}_{91}\right)=0.0167-0.0034=0.013 \text {. }
$$

The effect is economically significant, al though smaller in size than our preliminary estimate which assumed that the reduction in base money holdings would match, dollar-for-dollar, the decrease in required reserves.

The estimated effect of the 1992 reduction is only 0.0034 . While statistically significant with such a large sample, it is less than one-sixth of the 0.02 change in the marginal statutory reserve requirement ratio. This estimate suggests that banks in this size range reduced their holdings of Federal Reserve deposits little, if at all, following the decrease in the reserve-requirement ratio. There is some evidence of a smaller response by banks that had required clearing bal ance contracts. This difference seems consistent with our conjecture that required clearing balances are, for some banks at least, a low-cost type of excess reserves. Further, banks with required clearing balance contracts likely are purchasing paymentsrelated services from the Federal Reserve 
and need sufficient Federal Reserve deposits to avoid overdrafts.

Overall, for small and medium LBound banks, the estimated responses to the 1990-91 reduction are economically significant, while responses to the 1992 reduction are not. The insignificance of the latter coefficient for small banks is expected, since their marginal reserve ratio remained unchanged at 3 percent. While the 1992 year effect for the medium L-Bound banks is statistically significantly greater than zero, its small size makes it difficult to attribute the effect to changes in the marginal reserve requirement ratio. In part, the estimated effect may reflect banks' reaction to the lower federal funds rate that prevailed during 1992, relative to 1991. Below, we compare these responses to those of similar L-N onbound banks.

As a result of this analysis, small and medium-size L-Bound depository institutions are assumed to have been E-Bound prior to January 1991 and are included in RAM through December 1990, but are assumed to have become E-N onbound in January 1991 and are thereafter excluded from RAM. With the exclusion of these depository institutions, only about 5-1/2 percent of weekly reporting institutions, and 2 percent of all institutions (see Table 2 ), are included in the revised RAM adjustment for the St. Louis adjusted monetary base.

Regional and Large L-Bound Banks. On balance, regional and large L-Bound banks are estimated to have responded significantly to both the 1990-91 and 1992 reductions; in other words, they were $\mathrm{E}$ Bound. Preliminary estimates of the reductions' effects may be calculated, as above, from Table 3. Required reserves held against net transaction deposits were about 83 percent of these banks' total required reserves in 1990, and their ratios of total required reserves to net transaction deposits were about 12.2 and 13.9 percent, respectively. If the 1990-91 reductions in required reserves were reflected fully in reduced holdings of base money, we would project an effect of more than 0.02 . The estimated ANOVA effect for regional banks is

$$
\left(\hat{\lambda}_{90}-\hat{\lambda}_{91}\right)=0.0321-0.0128=0.0193,
$$

and for large banks is

$$
\left(\hat{\lambda}_{90}-\hat{\lambda}_{91}\right)=0.0364-0.0121=0.026 \text {. }
$$

Both are almost precisely what would occur if these banks matched the reduction in their required reserves with dollar-for-dollar reductions in their holdings of base money.

In contrast, these banks seem to have reduced their holdings of base money less than proportionately, following the April 1992 reduction in reserve requirements. The estimated coefficients, $\lambda_{92}$, for regional and large banks- 0.0128 and 0.0128 , respectively-are significantly greater than zero statistically and less than the 0.02 reduction in the marginal statutory requirement. Again, banks with required clearing balance contracts are esti mated to have reduced their holdings of base money less than other banks. The lower federal funds rate during 1992 likely attenuated the reduction in Federal Reserve deposits that otherwise would have followed the reserve-requirement reduction. In addition, the smaller estimated coefficient (relative to the statutory change of 0.02 ) likely reflects some large banks becoming E-N onbound after the 1990-91 and 1992 reductions. ${ }^{32}$

\section{Small and Medium-Size L-Nonbound}

Banks. Estimates for L-N onbound banks suggest economically insignificant responses to changes in reserve requirements since 1990. Table 3's summary statistics show that required reserves held against nontransaction deposits were about 40 percent and 30 percent, respectively, of the total required reserves held by these banks in 1990. The average aggregate ratios of required reserves to net transaction deposits at these banks were 4.1 percent and 6.2 percent, respectively, suggesting that these banks' ratios of base money to net transaction deposits might decrease by as much as 1.8 percent. The estimated AN OVA effects of the reduction -0.005 for small banks and 0.003 for medium bank - are fairly similar and less than one-third of the pre-

\footnotetext{
${ }^{32}$ See Feinman (1993) and Hilton, Cohen and Koonmen (1993).
} 
liminary estimate based on Table 3, under the assumption that the banks are $\mathrm{E}$ Bound. Considering the generally lower federal funds rate that prevailed during this period, we have difficulty attributing the change in these banks' base money holdings, relative to net transaction deposits, to changes in legal reserve ratios.

Like medium-size L-Bound banks, medium-size L-N onbound banks did not respond to the 1992 reduction in the reserve-requirement ratio on net transaction deposits. The estimated ANOVA effect, 0.0035 , is not economically different from zero.

\section{An ANOVA Model with Idiosyncratic Bank-Year Interactions}

The ANOVA model shown above includes a single fixed effect for each bank, $\alpha_{\mathrm{i}}$, and assumes that the response of all banks to the changes in statutory reserve requirements is the same, measured by $\lambda_{90}$ and $\lambda_{91}$. Because it seems unlikely that all banks responded in the same way, we estimated a second AN OVA model that permits idiosyncratic responses by each bank to the year effects:

${ }^{33}$ The ANOVA models are estimated with the GLM and REG procedure in SAS, version 6.11, on an HP Unix workstation.

${ }^{34}$ Medium-size L-Bound banks averaged about $\$ 80$ million in net transaction deposits (see Table 3), the first $\$ 3.6$ million subject to a zero reserve requirement ratio, the next $\$ 38.6$ million to a 3 percent ratio and, before the April 1992 reduction, the balance to a 12 percent ratio. Their ratio of base money to net transaction deposits would have decreased by about 1 percentage point if the banks had matched the reduction in their required reserves with a dollarfor-dollar reduction in their holdings of base money.

$$
\begin{aligned}
& y_{i j t}=\phi+\sum_{i=1}^{N-1}\left(\alpha_{i}-\alpha_{N}\right) D_{i j t}^{B}+ \\
& \sum_{i=1}^{N} \sum_{t=90}^{91}\left(\beta_{i t}-\beta_{i, 92}\right) D_{i j t}^{B} D_{i j t}^{Y}+ \\
& \sum_{j=1}^{12}\left(\gamma_{j}-\gamma_{13}\right) D_{i j t}^{p}+\xi D_{i j t}^{R}+\varepsilon_{i j t}
\end{aligned}
$$

where $y_{i j t}$ is the same as above. This model becomes the same as the previous AN OVA if the bank-year effects are constrained to be equal for all banks during each year, or in other words,

In the ANOVA, the effect of the 1990-91 reduction in reserve requirements is measured by

$$
\hat{\beta}_{\mathrm{i}, 90}-\hat{\beta}_{\mathrm{i}, 91}=\left(\hat{\beta}_{\mathrm{i}, 90}-\hat{\beta}_{\mathrm{i}, 92}\right)-\left(\hat{\beta}_{\mathrm{i}, 91}-\hat{\beta}_{\mathrm{i}, 92}\right),
$$
and the effect of the 1992 reduction by

$$
\beta_{1, \mathrm{t}}=\cdots=\beta_{\mathrm{N}, \mathrm{t}}=\frac{1}{\mathrm{~N}} \lambda_{\mathrm{t}}, \mathrm{t}=90,91 .
$$

$$
\hat{\beta}_{\mathrm{i}, 91}-\hat{\beta}_{\mathrm{i}, 92} .
$$

Distributions (histograms) of these individual bank-year interaction effects are shown in Figures 6-8. Summary statistics and hypothesis tests for this model are shown in Table $5 .{ }^{33}$ Although Parts $A$ and $B$ of Table 5 show estimates under the same alternative $L$-Bound classification criteria used in Tables 3 and 4, we limit our discussion to Part A. Figures 6-8 are based on the regressions summarized in Part $A$ of Table 5.

The null hypothesis that there was no change in the behavior of $y_{i j t}$ across 1990 , 1991, and 1992 is easily rejected by the Fstatistics reported in Table 5 . The estimated responses of individual small, medium, regional and large L-Bound banks to the 1990-91 reduction in reserverequirement ratios are shown, respectively, in panels $A$ and $C$ of Figures 6 and 7 (pages $\bullet \cdot$ and $\bullet \bullet$ ). The number of estimated coefficients plotted in each panel is shown in the panel title. On balance, $L$ Bound banks responded by significantly reducing their holdings of base money: Most of the shaded area in each distribution is well to the right of zero (marked by a vertical line). Substantial variation in the responses of individual banks is evident in the figures, in part because different banks held different proportions of transaction and nontransaction deposits (recall that the dependent variable is the ratio of the bank's base money holdings to its transaction deposits).

In contrast, the estimated response by L-Bound banks to the April 1992 reduction in reserve-requirement ratios, shown in panels $B$ and $D$ of Figures 6 and 7 , is more varied. As expected, the distribution for small L-Bound banks (panel B of Figure 6) is tightly centered about zero. Medium-size L-Bound banks (panel $D$ of Figure 6) also responded weakly to the change, most commonly reducing their ratios of base money to transaction deposits by about half of what would be implied if they had matched the decrease in their required reserves dollarfor-dollar. ${ }^{34}$ For regional-size banks ( panel 


\section{ANOVA Model Estimates for Weekly-Reporting Banks, with Bank-Year Interaction Effects}

\begin{tabular}{|c|c|c|c|c|c|c|}
\hline \multirow[b]{2}{*}{ Statistic } & \multicolumn{4}{|c|}{ L-Bound Banks } & \multicolumn{2}{|c|}{ L-Nonbound Banks } \\
\hline & Small & Medium & Regional & Large & Small & Medium \\
\hline \multicolumn{7}{|c|}{ A. Classified on Legal Reserve Status in 1992 and on Size in $1990^{1}$} \\
\hline $\begin{array}{l}\text { F Statistics } \\
\text { (numerator degrees of freedom) } \\
\text { for bank fixed effects } \\
p \text {-value }(P r>F) \\
\text { for bank-year fixed effect } \\
p \text {-value }(P r>F)\end{array}$ & $\begin{array}{c}42.9(1138) \\
0.0001 \\
14.0(2278) \\
0.0001\end{array}$ & $\begin{array}{l}269.4(511) \\
0.0001 \\
52.7(1024) \\
0.0001\end{array}$ & $\begin{array}{c}126.9(121) \\
0.0001 \\
20.3(244) \\
0.0001\end{array}$ & $\begin{array}{c}194.7(48) \\
0.0001 \\
100.9(98) \\
0.0001\end{array}$ & $\begin{array}{l}269.0(2208) \\
0.0001 \\
27.6(4418) \\
0.0001\end{array}$ & $\begin{array}{c}298.4(44) \\
0.0001 \\
21.3(90) \\
0.0001\end{array}$ \\
\hline $\begin{array}{c}\text { Coefficient Estimates (t-statistic) } \\
\text { Required Clearing Balance } \\
\text { p-value }(\operatorname{Pr}>|t|)\end{array}$ & $\begin{array}{l}0.005(1.3) \\
0.20\end{array}$ & $\begin{array}{l}0.010(12.0) \\
0.0001\end{array}$ & $\begin{array}{l}0.022(4.2) \\
0.0001\end{array}$ & $\begin{array}{l}0.018(9.2) \\
0.0001\end{array}$ & $\begin{array}{l}0.006(10.9) \\
0.0001\end{array}$ & $\begin{array}{l}0.014(4.1) \\
0.0001\end{array}$ \\
\hline $\begin{array}{l}\text { Summary Statistics } \\
\text { Model degrees of freedom } \\
\text { Error degrees of freedom } \\
\text { R-Squared }\end{array}$ & $\begin{array}{l}3429 \\
40991 \\
0.66\end{array}$ & $\begin{array}{l}1548 \\
18419 \\
0.91\end{array}$ & $\begin{array}{l}378 \\
4379 \\
0.82\end{array}$ & $\begin{array}{l}159 \\
1751 \\
0.92\end{array}$ & $\begin{array}{l}6639 \\
79511 \\
0.90\end{array}$ & $\begin{array}{c}147 \\
1607 \\
0.90\end{array}$ \\
\hline
\end{tabular}

B. Classified on Legal Reserve Status in 1990, 1991 and 1992, and on Size in 1990²

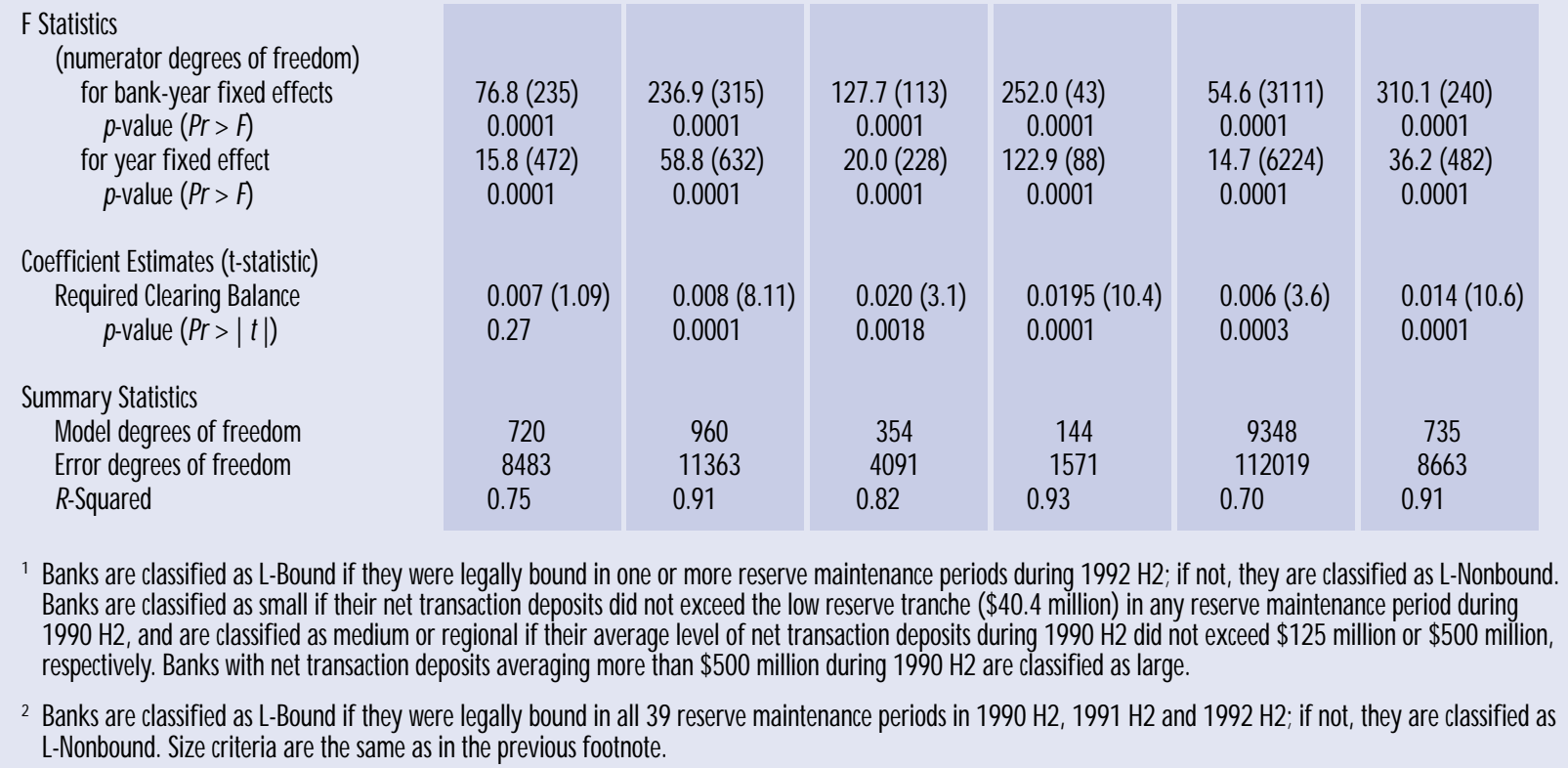

B of Figure 7), the ratio fell about 1-1/2 percentage points, close to what would be projected from their average net

transaction deposits of about $\$ 280$ million (see Table 3). Large L-Bound banks (panel D of Figure 7) most commonly reduced their base money holdings by about the full 2 percentage points.

The ANOVA effects for L-N onbound banks are shown in Figure 8 (see page $\bullet \bullet$ ).

Because these banks satisfied their statutory reserve requirement with vault 


\section{Figure 6}

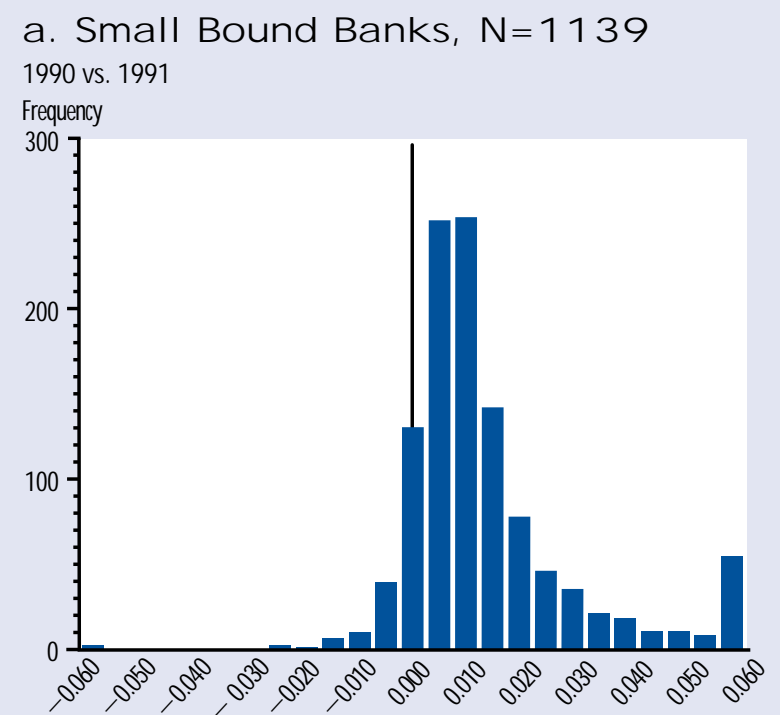

\section{c. Medium Bound Banks, N=512} 1990 vs. 1991

Frequency

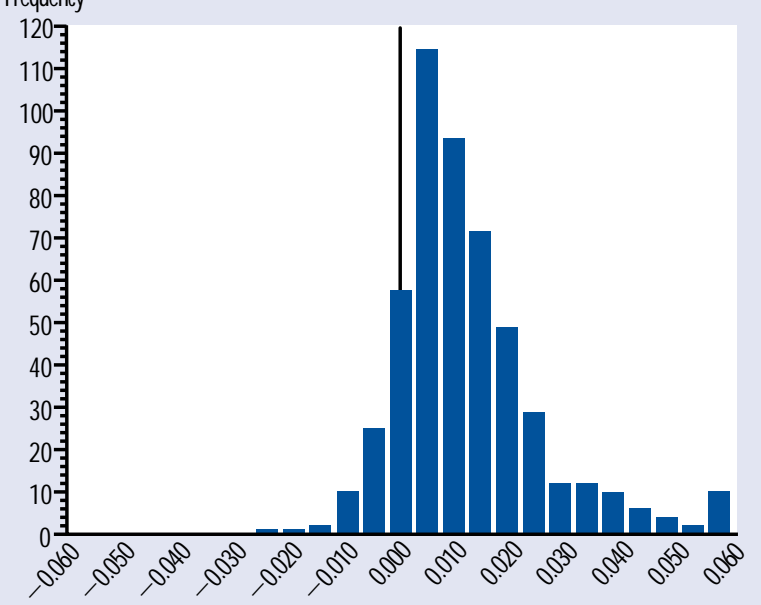

b. Small Bound Banks, $N=1139$ 1991 vs. 1992

Frequency

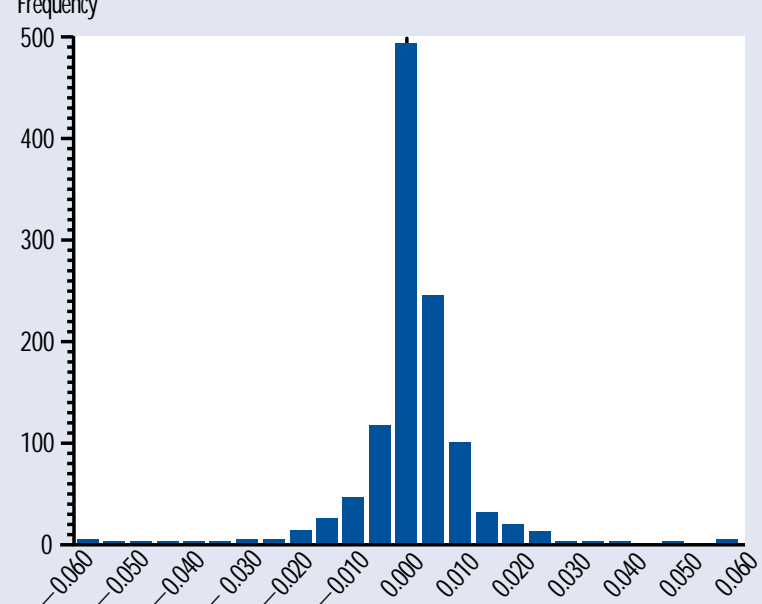

d. Medium Bound Banks, N=5 12 1991 vs. 1992

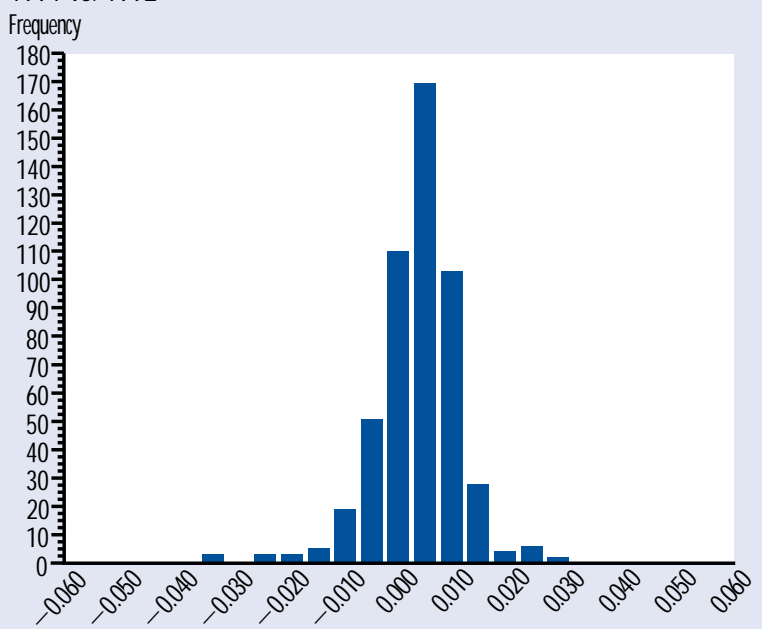

cash, we anticipated little reaction to the reductions in reserve-requirement ratios. Although there is some variety in effects for individual banks, the distributions for L-N onbound banks generally are symmetric about zero, for both the 199091 changes (panels A and C) and the 1992 change (panels B and D).

\section{Repeated-Measures A nalysis of Variance}

The panel, or longitudinal, structure of our data requires attention to the implied covariance structure of the data- generating process. Each bank in our sample is observed for 13 reserve maintenance periods in each of three years, 1990, 1991, and 1992. As such, it seems unlikely that the disturbances in our ANOVA models, $\varepsilon_{i \mathrm{it}}$, are independent and identically distributed. If they are not, the coefficient estimates are unbiased and inefficient, while the estimated covariance matrix is biased and inconsistent. An appropriate covariance structure likely would be block-diagonal, with a separate block for each bank. A test for the responses of depository institutions which 


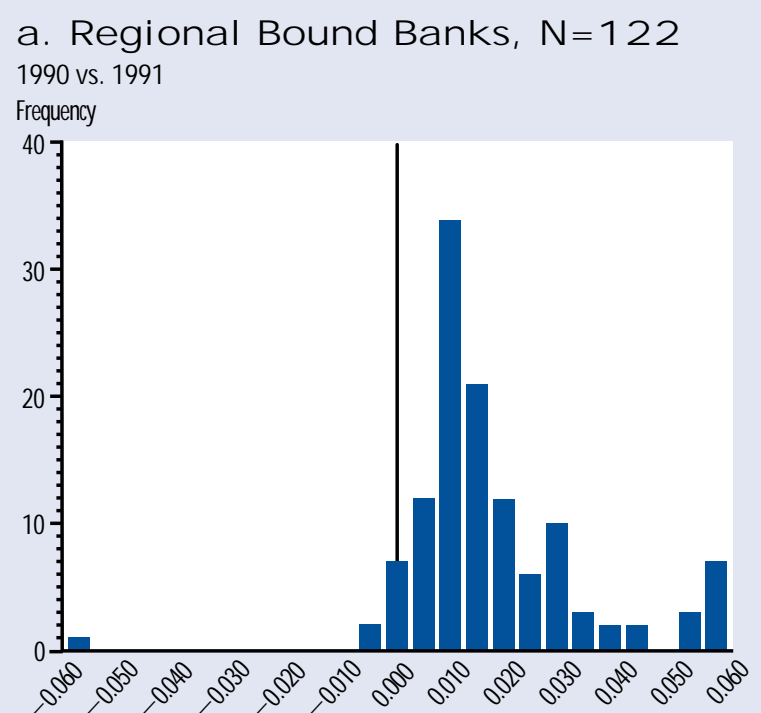

\section{Large Bound Banks, $\mathbf{N}=\mathbf{4 9}$}

1990 vs. 1991

Frequency

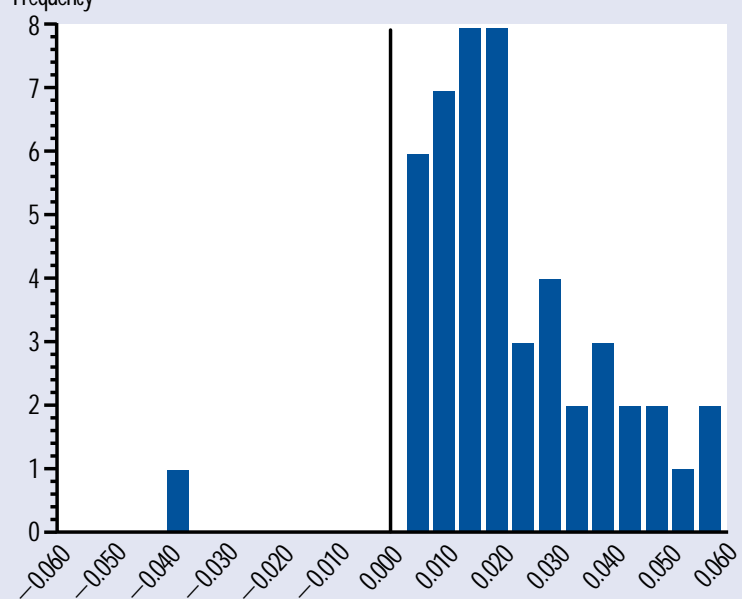

b. Regional Bound Banks, $\mathbf{N}=122$ 1991 vs. 1992

Frequency

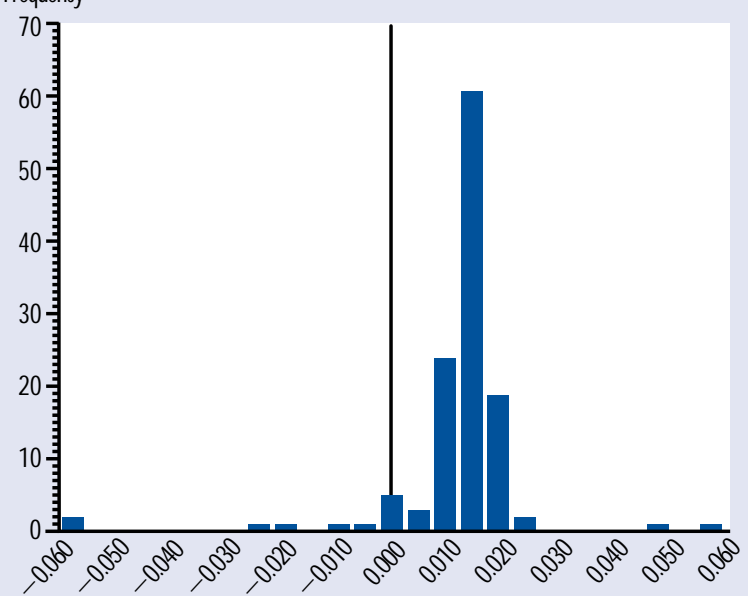

d. Large Bound Banks, $\mathbf{N}=49$

1991 vs. 1992

Frequency

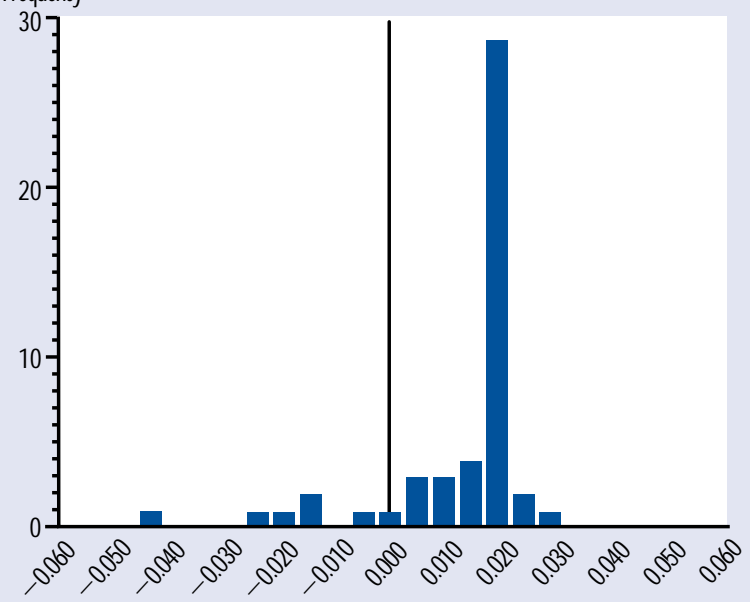

incorporates this block-diagonal covariance structure may be constructed by viewing the banks as if they were clinical subjects engaged in a laboratory experiment. It is commonplace in clinical studies to measure certain characteristics of subjects both pre- and post-treatment, asking whether the change in the measurement for each subject, when averaged across all subjects, is statistically significant. Since there are multiple observations on each subject, the models are widely referred to as repeated measures models. ${ }^{35}$ In these models, the repeated observations for each subject are treated as multiple time series, and the disturbance is assumed to be multivariate normal.

In our data, we observe the ratio of base money to net transaction deposits for each bank during thirteen reserve maintenance periods in each of three years: 1990, 1991 and 1992. In the repeated measures ANOVA, the observations for each year are treated as thirteen realizations of a single time series process; pooled across the three years, the observations are regarded as a multiple time series process composed of three univariate processes. The data for
${ }^{35}$ See Crowder and Hand (1990), Diggle, Liang and Zeger (1994), or Davidian and Giltinan (1995). An earlier reference is Hsiao (1986). 


\section{Figure 8}
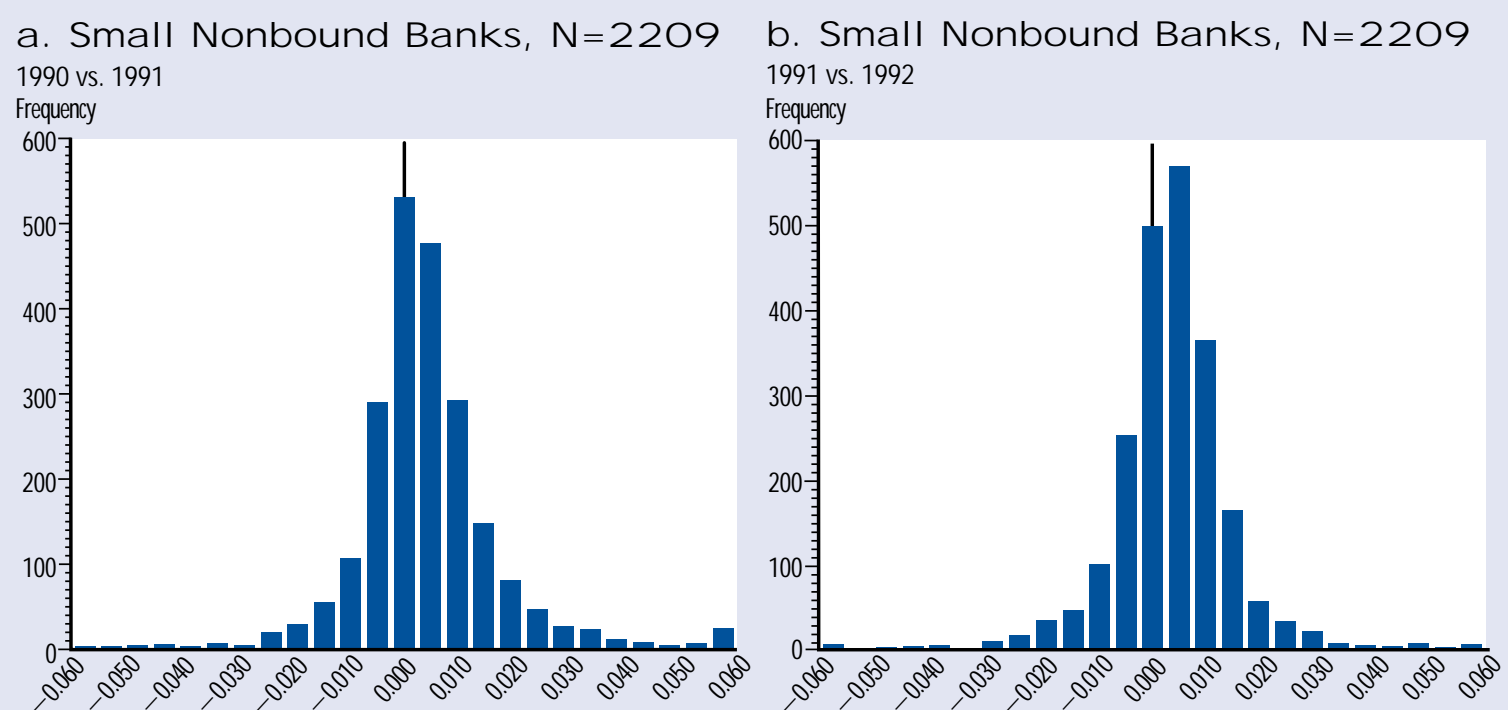

\section{c. Medium Nonbound Banks, $N=45$} 1990 vs. 1991

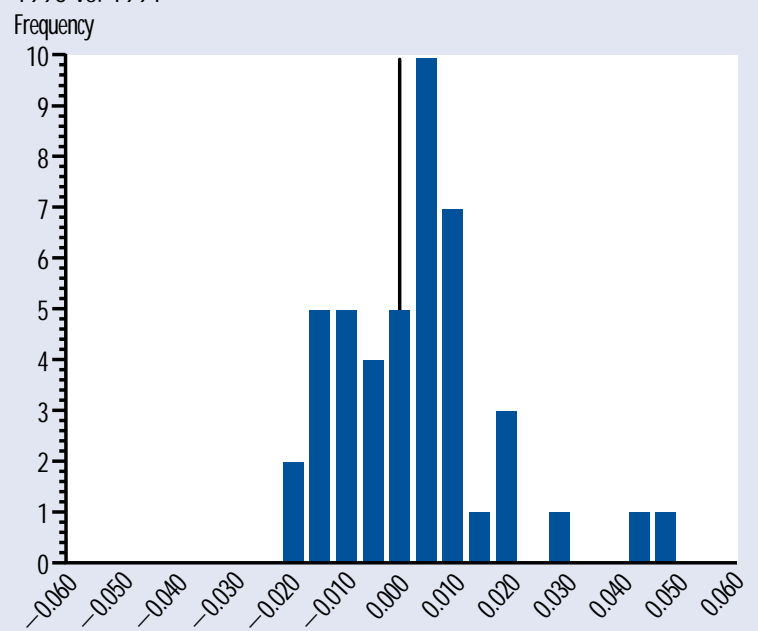

\section{d. Medium Nonbound Banks, $N=45$}

1991 vs. 1992

Frequency

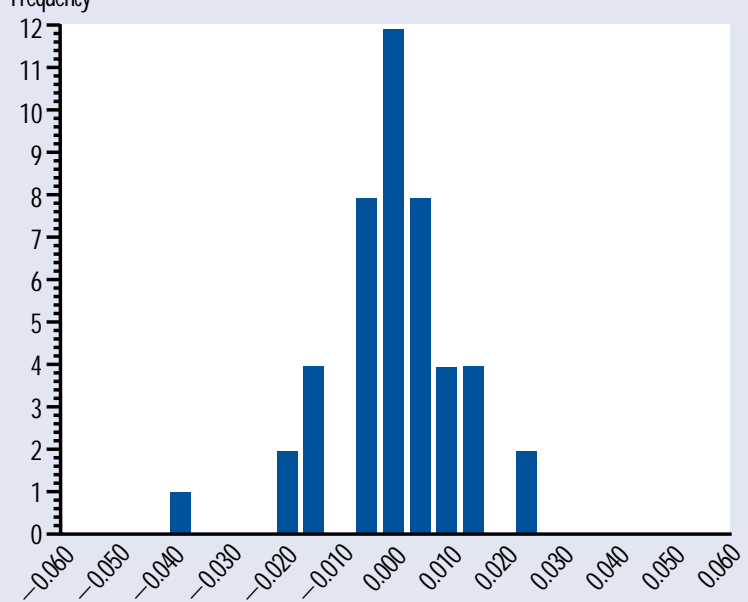

1990-91 form a pre- and post-treatment contrast for the 1990-91 reserve requirement reduction, and the data for 1991-92 form a similar contrast for the A pril 1992 reduction. Inferences regarding the response of various groups of banks to the reserve requirement changes are made by testing for the existence of significant interaction effects across years between (and among) each individual year's reserve maintenance-period effects.

Repeated measures AN OVA results are shown in Table 6 and in Figures 9 and 10. Two tests are shown in each of Parts $A$ and $B$ in the table. The first is based on an esti- mated multivariate ANOVA, or MANOVA, model wherein the dependent variable is the vector $\left[\mathrm{y}_{\mathrm{i}, 90,9}, \mathrm{y}_{\mathrm{i}, 91,91} \mathrm{y}_{\mathrm{i}, 92,}\right]^{\prime}$, the explanatory variables are dummy variables representing each reserve maintenance period and the presence of a required clearing balance contract, and the disturbance vector for each bank is assumed multivariate normal without any restrictions on its covariance matrix. The value of Wilks' lambda, a multivariate analog of more familiar F-tests, suggests rejection of the hypothesis that coefficients on the period dummy variables are the same in all three equations. The second 


\section{Table 6}

Test Statistics for Repeated Measures ANOVA Models Null Hypothesis: No Year-Period Interaction Effect for 1990,1991 and 1992

\begin{tabular}{|c|c|c|c|c|c|c|}
\hline \multirow[b]{2}{*}{ Statistic } & \multicolumn{4}{|c|}{ L-Bound Banks } & \multicolumn{2}{|c|}{ L-Nonbound Banks } \\
\hline & Small & Medium & Regional & Large & Small & Medium \\
\hline
\end{tabular}

A. Classified on Legal Reserve Status in 1992 and on Size in $1990^{1}$

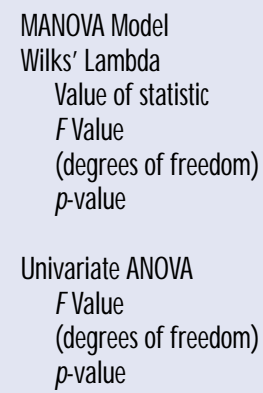

\begin{tabular}{|c|c|c|c|c|c|}
\hline & & & & \\
0.996 & 0.909 & 0.957 & 0.775 & 0.982 & 0.924 \\
2.02 & 25.1 & 2.67 & 6.52 & 20.1 & 1.77 \\
\hline$(24,27310)$ & $(24,12262)$ & $(24,2902)$ & $(24,1150)$ & $(24,52990)$ & $(24,1054)$ \\
0.0023 & 0.0001 & 0.0001 & 0.0001 & 0.0001 & 0.013 \\
& & & & & \\
\hline 1.98 & 27.8 & 1.51 & 5.92 & 20.45 & 1.75 \\
\hline$(24,27312)$ & $(24,12264)$ & $(24,2904)$ & $(24,1152)$ & $(24,52992)$ & $(24,1056)$ \\
0.0029 & 0.0001 & 0.0543 & 0.0001 & 0.0001 & 0.014 \\
& & & & & \\
\hline
\end{tabular}

B. Classified on Legal Reserve Status in 1990, 1991 and 1992, and on Size in $1990^{2}$

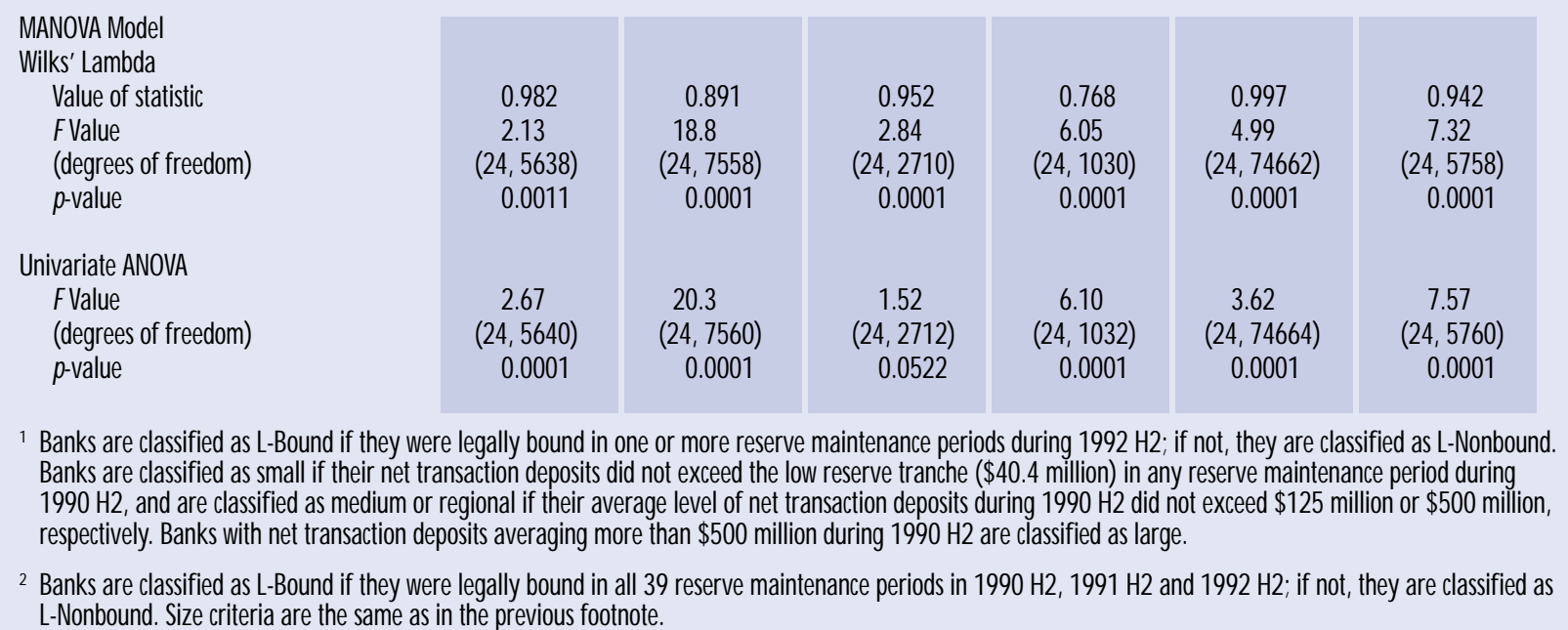
L-Nonbound. Size criteria are the same as in the previous footnote.

test shown in the table is based on an estimated single-equation regression that includes interaction effects between the reserve-maintenance period dummy variables and the year dummy variables (for 1990 and 1991, relative to 1992). The null hypothesis of no year effects is again strongly rejected. The test statistics shown in Parts $A$ and $B$ of Table 6 reinforce the inferences obtained from the fixed-effects ANOVAs: L-N onbound banks also were ENonbound at the time of the 1990-91 reduction, and larger L-Bound institutions responded more strongly to the reductions than did smaller banks.

Our final repeated measures test is graphical, shown in Figures 9 and 10. The test is based on the differences $D_{i j, 91}=y_{i j, 91}-y_{i j, 90}$ and $D_{i j, 92}=y_{i j, 92}-y_{i j, 91}$, respectively, where $y_{i j t}$ is the ratio of base money to net transaction deposits held by depository institution $i$ in reserve maintenance period $j, j=1, \ldots 13$, during year $t$, $t=90,91$, 92. Letting $D$.jt denote the mean of the $D_{i j t}$ for maintenance period $j,(t=91$, 92 ) then under suitable regularity condi- 


\section{BeVIEII}

November/ December 1996

\section{Figure 9}

Confidence Intervals

For the Difference between 1990 and 1991 Monetary Base-to-Net Transaction Deposit Ratios.

\section{Small}
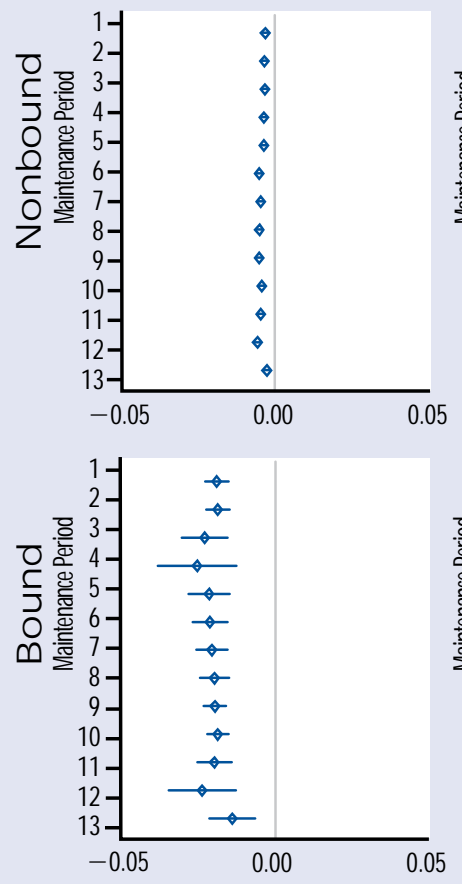

Medium

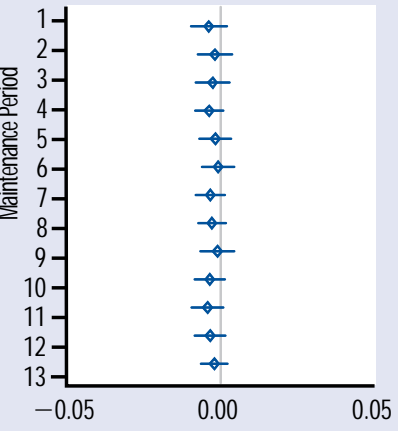

Regional

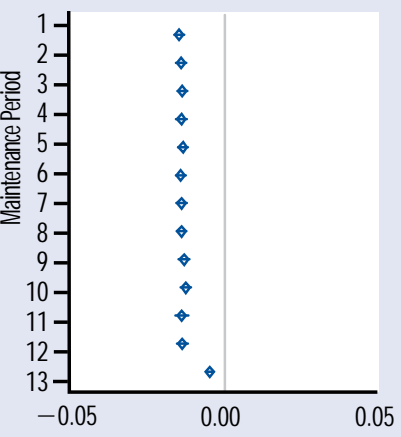

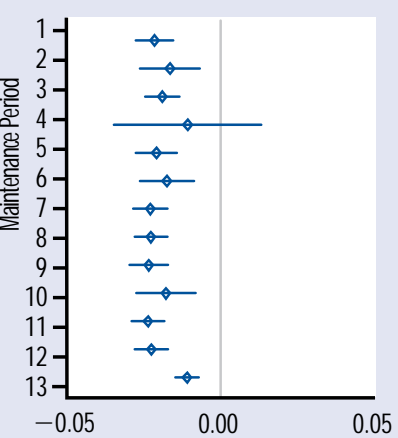

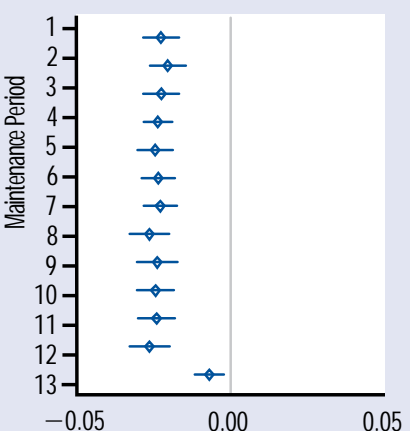

tions a $(100-\gamma)$ percent confidence interval for the null hypothesis that $D_{\cdot \cdot \mathrm{jt}}=0$ is

$$
\begin{gathered}
\left(D_{\cdot j}-t_{(1+\gamma) / 2} \sqrt{\frac{\sum_{i}\left(D_{i j}-D_{\cdot j}\right)^{2}}{n(n-1)}}, D_{\cdot j}+\right. \\
t_{(1+\gamma) / 2} \sqrt{\frac{\sum_{i}\left(D_{i j}-D_{\cdot j}\right)^{2}}{n(n-1)}},
\end{gathered}
$$

where $t_{(1+\gamma / 2}$ is the $[(1+\gamma) / 2]^{\text {th }}$ quantile of the t distribution with $\mathrm{n}-1$ degrees of freedom. ${ }^{36}$ These confidence intervals are plotted as horizontal line segments in Figures 9 and 10. The length of each line segment shows the width of the confidence interval, the numbers on the vertical axis index the reserve maintenance

${ }^{36}$ See for example Mood, Graybill and Boes (1974), p. 387. period $j$, and the means $D$.jt are indicated by the large dots on each line. We show the confidence intervals graphically (rather than reporting significance levels or $p$ values for rejection/acceptance of the null hypothesis of no response to a change in the reserve requirement ratio) because inferences drawn from a graphical presentation likely are more robust to deviations from the regularity conditions that justify use of the (asymptotic) t-distribution in construction of the intervals. A graphical presentation also is somewhat easier to interpret than classical test statistics when between-bank, within-group variances are small, as reflected in the short length of the confidence intervals.

Figure 9 shows banks' responses to the 1990-91 reduction in reserve-requirement ratios. The results are clear: L-Bound banks, shown in the second row of the figure, reduced their holdings of base money relative to net transaction deposits by about -0.02 , close to the estimates obtained in the ANOVA models, while L- 


\section{REVIEW}

November/ December 1996

\section{Figure 10}

Confidence Intervals

For the Difference between 1991 and 1992 Monetary Base-to-Net Transaction Deposit Ratios.

Small

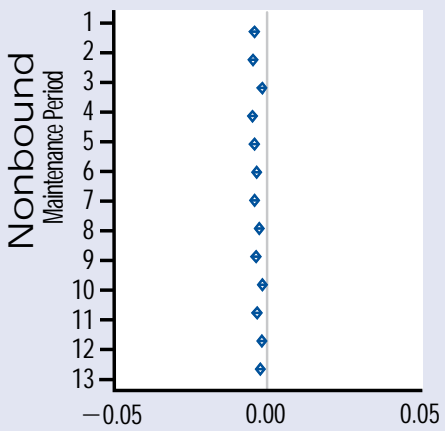

Medium

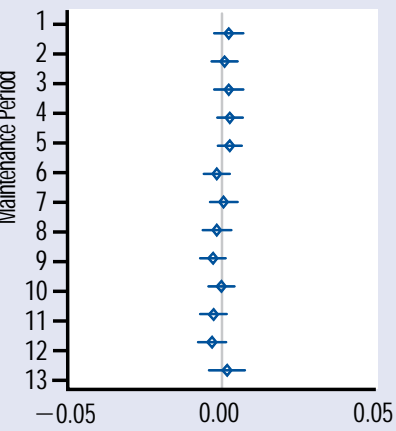

Regional

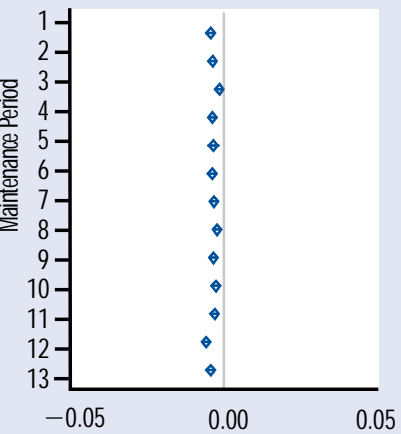

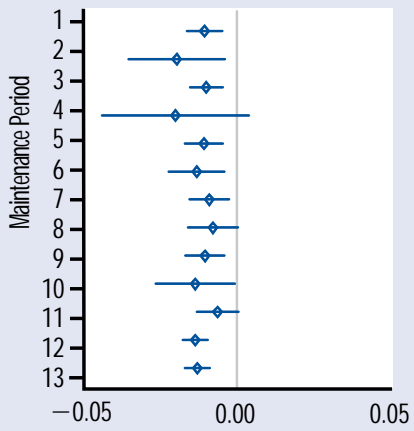

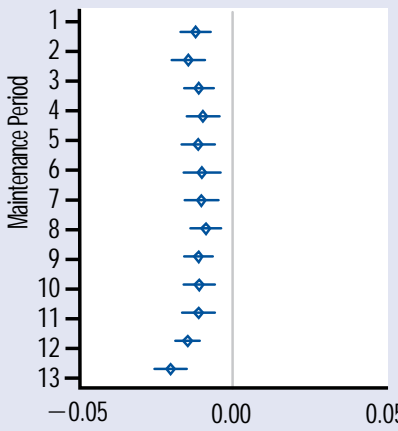

Nonbound institutions did not respond. Of special interest is the confidence interval for the change between the thirteenth reserve maintenance periods in 1990 and in 1991. The reserve-requirement reduction was phased in, with only one-half of the reduction in force during the final reserve maintenance period of 1990 . EBound banks would be expected to respond to the phased reduction by displaying a smaller response for this thirteenth period than for the other twelve periods. Such a response is distinct for $L$-Bound banks and absent for L-N onbound banks. We conclude that: (1) L-N onbound depository institutions likely were $E-N$ onbound before the 1990-91 reduction, and hence should be excluded from RAM; and (2) L-Bound institutions generally were E-Bound, and responded as expected to the reduction in requirements.

Figure 10 shows similar intervals for the April 1992 reduction in reserve require- ments. Small and medium-size L-N onbound and L-Bound banks did not respond: their confidence intervals either include, or are very close to, the origin. Although larger L-Bound banks reduced their holdings of base money, on average their response was less than the 0.02 reduction in the statutory requirement. The less-than-proportionate response perhaps reflects the falling federal funds rate; it might also be signalling, however, that the banks were becoming, or had become, E-N onbound. The latter hypothesis is supported by the observation that, by the end of 1992, about half of these banks had agreed, through required clearing balance contracts, to maintain Federal Reserve deposits in excess of amounts necessary to satisfy their statutory reserve requirements. We conclude that by the end of 1992 only a small number of U.S. depository institutions found statutory reserve requirements governing their demand for base money. 


\section{CONCLUSIONS}

The evidence presented in this article suggests that depository institutions' demand for the monetary base has changed sharply since implementation of the Monetary Control Act in 1980. Increasingly, depository institutions are maintaining deposits at Federal Reserve Banks to settle interbank payments, not to satisfy statutory required reserves. Measures of the monetary base must be expanded to include all the deposits held by domestic depository institutions at Federal Reserve Banks. The exclusion of the nominal amount of required clearing balance contracts from the old St. Louis measure and from the Board of Governors' measure, albeit perhaps justified in the early 1980 s, is today incorrect.

The importance of statutory reserve requirements as a determinant of depository institutions' demand for base money also has diminished since 1980. If the adjusted monetary base is to remain interpretable as an index of quantitative monetary policy actions, care must be exercised when combining the effects of changes in reserve requirements with changes in the monetary base. In particular, the RAM adjustment included in the St. Louis adjusted monetary base must be redefined so as to include only those depository institutions that respond to changes in statutory reserve requirements by changing their holdings of base money, or in other words, are EBound. Both the apparently less than dollar-for-dollar adjustment of many large banks to the April 1992 reduction in reserve requirements and the continuing spread of OCD-based sweep programs suggest that few, if any, depository institutions will be E-Bound in the future.

[Editor's N ote: In September 1996, the Federal Reserve Bank of St. Louis began publishing the new adjusted monetary base measure that is presented in this paper.]

\section{REFERENCES}

Advisory Commission on Monetary Statistics. Improving the Monetary Aggregates, Board of Governors of the Federal Resenve System, 1976.

Andersen, Leonall C., and Jerry L. Jordan. "The Monetary Base - Explanation and Analytical Use," this Review (August 1968), pp. 7-11.

Anderson, Richard G., and Kenneth A. Kavajecz. "A Historical Perspective on the Federal Reserve's Monetary Aggregates: Definition, Construction and Targeting," this Review (March/ April 1994), pp. 1-31.

and Robert H. Rasche. "A Revised Measure of the St. Louis Adjusted Monetary Base," this Review (March/ April 1996)(1996a), pp. 3-13.

and _. _. _. " "Redefining the Adjusted Monetary Base in an Era of Financial Change," Research Working Paper 96-012, Federal Reserve Bank of St. Louis, October 1996. (1996b)

and "What Do Money Market Models Tell Us About How to Implement Monetary Policy?" Journal of Money, Credit and Banking (November 1982), pp. 796-828.

James Johannes, and Robert H. Rasche. "A New Look at the Relationship Between Time Series and Structural Models," Journal of Econometrics (October 1983), pp. 234-51.

Balbach, Anatol B., and Albert E. Burger. "Derivation of the Monetary Base," this Review (November 1976), pp. 2-8.

Bank for International Settlements. Payments Systems in the Group of Ten Countries, Basle, Switzerland, December 1993.

Bank of Canada. "Implications of Monetary Policy in the Absence of Reserve Requirements," Discussion Paper No. 1, September 1987.

. . "The Implementation of Monetary Policy in a System with

Zero Reserve Requirements," Discussion Paper No. 2, February 1989

"The Implementation of Monetary Policy in a System with Zero Reserve Requirements," Discussion Paper No. 3, May 1991, revised September 1991.

Brunner, Karl. "A Schema for the Supply Theory of Money," International Economic Review (January 1961), pp. 79-109.

and Allan Meltzer. " Liquidity Traps for Money, Bank Credit, and Interest Rates," Joumal of Political Economy, (Jan.Feb. 1968), pp. 1-37. Reprinted in Monetary Economics, Karl Brunner and Allan $\mathrm{H}$. Meltzer, eds., Oxford: Basil Blackwell, 1989.

Burger, Albert E. The Money Supply Process, Wadsworth Publishing Company, 1971.

and Robert H. Rasche. "Revision of the Monetary Base," this Review (July 1977), pp. 13-27.

Cagan, Phillip. Determinants and Effects of Changes in the Money Stock, 1875-1960, National Bureau of Economic Research, 1965.

Crowder, M.J., and D.J. Hand. Analysis of Repeated Measures, Chapman and Hall, 1990.

Federal Reserve bank of St. Louis 
Davidian, Marie, and David M. Giltinan. Nonlinear Models for Repeated Measurement Data, Chapman and Hall, 1995.

Deutsche Bundesbank. The Monetary Policy of the Bundesbank, Frankfurt: Deutsche Bundesbank, 1994.

Diggle, Peter J., Kung-Yee Liang, and Scott L. Zeger. Analysis of Longitudinal Data, Oxford: Clarendon Press, 1994.

Federal Reserve Bulletin, various issues.

Feinman, Joshua. "Reserve Requirements: Histony, Current Practice and Potential Reform," Federal Reserve Bulletin (June 1993), pp. 569-89.

Friedman, Mitton, and Anna J. Schwartz. A Monetary History of the United States, 1867-1960, Princeton University Press, 1963.

Gambs, Carl M, and Robert H. Rasche. "Costs of Reserves and the Relative Size of Member and Nonmember Bank Demand Deposits," Journal of Monetary Economics (November 1978), pp. 715-23.

Gilbert, R. Alton. "Two Measures of Reserves: Why Are They Different?" this Review (June/ July 1983), pp. 16-25.

_. _. _. . "Effectiveness of State Reserve Requirements," this Review (September 1978), pp. 16-28.

and Jean M. Lovati. "Bank Reserve Requirements and Their Enforcement: A Comparison Across States," this Review (March 1978), pp. 22-31.

and Bruce J. Summers, "Clearing and Settlement of U.S. Dollar Payments: Back to the Future?" this Review (Sept./ Oct. 1996), pp. 3-27.

Hancock, Diana, and James A. Wilcox. "Intraday Management of Bank Reserves: The Effects of Caps and Fees on Daylight Overdrafts." Journal of Money, Credit and Banking, (November 1996, Part 2), pp. 870-908.

Hilton, Spence, Ari Cohen, and Ellen Koonmen. "Expanding Clearing Balances," in Reduced Reserve Requirements: Alternatives for the Conduct of Monetary Policy and Reserve Management, Ann-Marie Muelendyke, ed., Federal Resenve Bank of New York, 1993.

Hsiao, Cheng. Analysis of Panel Data, Cambridge University Press, 1986.

Kohn, Donald L. "Comments on Anderson and Rasche," this Review (19), pp. $\cdot$.

Mood, Alexander M., Franklin A. Graybill, and Duane C. Boes. Introduction to the Theory of Statistics, McGraw Hill, 1974.

Rasche, Robert H., and James M. Johannes. Controlling the Growth of Monetary Aggregates, Kluwer Academic Publishers, 1985.

Richards, Heidi Willman. "Daylight Overdraft Fees and the Federal Reserve's Payment System Risk Policy," Federal Reserve Bulletin (December 1995), pp. 1065-77.

Stevens, E.J. "Required Clearing Balances," Economic Review, Federal Reserve Bank of Cleveland (vol. 29, no. 4, 1993), pp. 2-14.
Tatom, John A. "Issues in Measuring An Adjusted Monetary Base," this Review (December 1980), pp.11-29. 